\title{
Microglia in mouse retina contralateral to experimental glaucoma exhibit multiple signs of activation in all retinal layers
}

Blanca Rojas 1,2, Beatriz I Gallego 1,3, Ana I Ramírez ${ }^{1,3}$, Juan J Salazar ${ }^{1,3}$, Rosa de Hoz ${ }^{1,3}$, Francisco J Valiente-Soriano ${ }^{4}$, Marcelino Avilés-Trigueros ${ }^{4}$, Maria P Villegas-Perez ${ }^{4}$, Manuel Vidal-Sanz ${ }^{4}$, Alberto Triviño ${ }^{1,2}$ and José M Ramírez ${ }^{1,2^{*}}$

\begin{abstract}
Background: Glaucomatous optic neuropathy, a leading cause of blindness, can progress despite control of intraocular pressure - currently the main risk factor and target for treatment. Glaucoma progression shares mechanisms with neurodegenerative disease, including microglia activation. In the present model of ocular hypertension (OHT), we have recently described morphological signs of retinal microglia activation and MHC-II upregulation in both the untreated contralateral eyes and $\mathrm{OHT}$ eyes. By using immunostaining, we sought to analyze and quantify additional signs of microglia activation and differences depending on the retinal layer.

Methods: Two groups of adult Swiss mice were used: age-matched control (naïve, $n=12)$, and lasered $(n=12)$. In the lasered animals, both $\mathrm{OHT}$ eyes and contralateral eyes were analyzed. Retinal whole-mounts were immunostained with antibodies against Iba-1, MHC-II, CD68, CD86, and Ym1. The Iba-1+ cell number in the plexiform layers (PL) and the photoreceptor outer segment (OS), Iba-1+ arbor area in the PL, and area of the retina occupied by Iba-1+ cells in the nerve fiber layer-ganglion cell layer (NFL-GCL) were quantified.

Results: The main findings in contralateral eyes and OHT eyes were: i) ameboid microglia in the NFL-GCL and OS; ii) the retraction of processes in all retinal layers; iii) a higher level of branching in PL and in the OS; iv) soma displacement to the nearest cell layers in the PL and OS; v) the reorientation of processes in the OS; vi) MHC-II upregulation in all retinal layers; vii) increased CD68 immunostaining; and viii) CD86 immunolabeling in ameboid cells. In comparison with the control group, a significant increase in the microglial number in the PL, OS, and in the area occupied by Iba-1+ cells in the NFL-GCL, and significant reduction of the arbor area in the PL. In addition, rounded Iba-1+CD86+ cells in the NFL-GCL, OS and Ym1+ cells, and rod-like microglia in the NFL-GCL were restricted to OHT eyes.

Conclusions: Several quantitative and qualitative signs of microglia activation are detected both in the contralateral and $\mathrm{OHT}$ eyes. Such activation extended beyond the $\mathrm{GCL}$, involving all retinal layers. Differences between the two eyes could help to elucidate glaucoma pathophysiology.
\end{abstract}

Keywords: Microglia, Glaucoma, Retina, Mouse, Inflammation

\footnotetext{
*Correspondence: ramirezs@med.ucm.es

${ }^{1}$ Instituto de Investigaciones Oftalmológicas Ramón Castroviejo, Facultad de Medicina, Pab Vl, 4a, Avenida Complutense s/n, Universidad Complutense de Madrid, 28040 Madrid, Spain

2Departamento de Oftalmología y ORL, Facultad de Medicina, Avenida

Complutense s/n, Universidad Complutense de Madrid, 28040 Madrid, Spain

Full list of author information is available at the end of the article
}

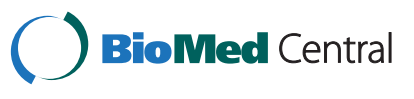

(c) 2014 Rojas et al.; licensee BioMed Central Ltd. This is an Open Access article distributed under the terms of the Creative Commons Attribution License (http://creativecommons.org/licenses/by/4.0), which permits unrestricted use, distribution, and reproduction in any medium, provided the original work is properly credited. The Creative Commons Public Domain Dedication waiver (http://creativecommons.org/publicdomain/zero/1.0/) applies to the data made available in this article, unless otherwise stated. 


\section{Background}

Glaucoma is a disease in which intraocular pressure (IOP) has been traditionally considered the major risk factor $[1,2]$. Although it is known that IOP increase is not the only risk factor for glaucoma, it remains the main target in the treatment of glaucomatous neurodegeneration [3]. However, in some patients, optic-nerve degeneration reportedly progresses despite IOP control [4]. Recent studies indicate that glaucomatous disease can also be induced by an auto-immune response [5,6]. These observations suggest that we should consider glaucoma not as a disease involving raised pressure, but as a disease in which neurological sensitivity to pressure itself is independent of the magnitude [7]. Glaucoma is currently considered a neurodegenerative disease [8]. Taking into account that the retina and the optic nerve are projections of the central nervous system, it is not surprising that glaucoma could share mechanisms, such as neurodegeneration progression, with neurodegenerative diseases of diverse etiologies [9]. It has been reported that in glaucoma, disease progression occurs through mechanisms integrated in neuronal degenerative processes of compartmentalization [10], in which the microglia are a common cellular element that is activated.

Microglia are central nervous system resident innate immune cells, endowed with sensor and effector functions as well as with phagocytic capacity during physiological and pathological conditions [11,12]. These cells respond to neuronal stress or injury by adopting a so-called activated state, in which they progress from a resting mode to an activated phenotype $[13,14]$. The activated phenotype includes alterations in cellular morphology, changes in the structure of the cellular processes, tissue distribution, migratory characteristics, proliferation, expression of various growth factors and cytokines, or phagocytic activity.

Reactive microglia have been detected in the retina and optic nerve from axotomized eyes [15-23], after ischemia and reperfusion injury [24-27], in genetic or inducible ocular hypertension models [28-36], and in human glaucoma [37-39]. Microglial activation is thought to be a major contributor to neuronal death. The addition of minocycline (which inactivates microglia) has been shown to have neuroprotective effects, delaying retinal ganglion cell (RGC) death and axon loss in different models of glaucoma [40-42]. However, the mechanisms controlling microglial recruitment and activation in human glaucoma or animal models have not been established, and it is unclear when during the course of the disease the microglia undergo these changes [12].

In the mouse model of unilateral laser-induced ocular hypertension, morphological signs of activation and upregulation of major histocompatibility complex class II (MHC-II) have been reported in both treated and the normotensive untreated contralateral eyes [36]. However, more specific data concerning microglia activation in this model, and differences depending on the retinal layer remain unknown.

The aim of the present study is to analyze, in addition to variable morphology in the different layers of the retina, different signs of microglial activation both in contralateral eyes and in laser-induced OHT eyes, specifically: migration, microglia cell number, cell arbor area in the plexiform layers, area occupied by Iba- $1+$ cells in the NFL-GCL, and upregulation of activation markers (MHC-II, CD68, CD86, and $Y m 1)$.

\section{Materials and Methods \\ Ethics statement}

Mice were treated in accordance with Spanish law and the Guidelines for Humane Endpoints for Animals Used in Biomedical Research. This study was approved by the Ethics Committee for Animal Research of Murcia University and the Animal Health Service of the Murcia Regional Ministry of Agriculture and Water (approval ID number: A1310110807). In addition, animal procedures followed institutional guidelines, European Union regulations for the use of animals in research, and the Association for Research in Vision and Ophthalmology (ARVO) statement for the use of animals in ophthalmic and vision research.

\section{Animals and anesthetics}

The experiments were performed on adult male albino Swiss mice (between 40 and $45 \mathrm{~g}$ ) obtained from the breeding colony of the University of Murcia (Murcia, Spain). The animals were housed in temperature- and light-controlled rooms with a 12 hours light/dark cycle and ad libitum access to food and water. Light intensity within the cages ranged from 9 to 24 lux. All surgical procedures were performed under general anesthesia induced with an intraperitoneal (ip) injection of a mixture of ketamine $\left(75 \mathrm{mg} / \mathrm{kg}\right.$, Ketolar ${ }^{\oplus}$, Parke-Davies, Barcelona, Spain) and xylazine $\left(10 \mathrm{mg} / \mathrm{kg}\right.$, Rompún ${ }^{\circ}$ Bayer, Barcelona, Spain). During recovery from anesthesia, the mice were placed in their cages and an ointment containing tobramycin (Tobrex ${ }^{\circ}$; Alcon, Barcelona, Spain) was applied to the cornea to prevent corneal desiccation and infection. Additional measures were taken to minimize discomfort and pain after surgery. The animals were killed with an ip overdose of pentobarbital (Dolethal Vetoquinol ${ }^{\circ}$, Especialidades Veterinarias, Alcobendas, Madrid, Spain).

\section{Experimental groups}

Two groups of mice were considered for study: an agematched control (naïve, $\mathrm{n}=12$ ) and a lasered group ( $\mathrm{n}=$ 12) that was killed two weeks after lasering. 
Induction of ocular hypertension and IOP measurements

To induce OHT, the left eyes of anesthetized mice were treated in a single session with a series of diode laser (Viridis Ophthalmic Photocoagulator-532 nm, Quantel Medical, Clermont-Ferrand, France) burns, following previously described methods $[43,44]$. Briefly, the laser beam was directly delivered without any lenses, aimed at the limbal and episcleral veins. The spot size, duration, and power were between 50 and $100 \mu \mathrm{m}, 0.5$ seconds, and $0.3 \mathrm{~W}$, respectively. Each eye received between 55 and 76 burns.

With the mice under deep anesthesia, the IOP was measured in both eyes with a rebound tonometer (Tono-Lab, Tiolat, Helsinki, Finland) [43,45-47] prior to and 24 hours, 48 hours, and 1 week after laser treatment for the lasered group, and before being killed for the naïve group. At each time point, six consecutive readings were taken for each eye and averaged. To avoid fluctuations of the IOP due to the circadian rhythm in albino Swiss mice [48], or due to the rise of the IOP itself [49], we tested the IOP consistently around the same time, preferentially in the morning and directly after deep anesthesia in all animals (lasered group and naïve).

\section{Immunohistochemistry}

The mice were deeply anesthetized, perfused transcardially through the ascending aorta first with saline and then with $4 \%$ paraformaldehyde in $0.1 \mathrm{M}$ phosphate buffer (PB) (pH 7.2 to 7.4). The orientation of each eye was carefully maintained with a suture placed on the superior pole immediately after deep anesthesia and before perfusion fixation [43]. Moreover, upon dissection of the eye, the insertion of the rectus muscle and the nasal caruncle were used as additional landmarks [50]. The eyes were post-fixed for two hours in the same fixative and kept in sterile 0.1 M PB. Retinas were then dissected and processed as retinal whole-mounts [51].

For the analysis of the microglia population in the mice retina and the expression of MHC class II molecules, retinal whole-mounts from naïve $(\mathrm{n}=3)$ and OHT eyes $(n=3)$, and their contralateral eyes $(n=3)$, were double immunostained, as described elsewhere [36]. The following primary antibodies were used for immunostaining: rabbit anti-Iba-1 (Wako, Osaka, Japan) in a 1:500 dilution and rat anti-mouse MHC class II (I-A/I-E) (eBioscience; San Diego, California, United States) in a 1:100 dilution. Binding sites of the primary antibodies were visualized with the corresponding secondary antibodies: donkey anti-rabbit Alexa Fluor 594 (Invitrogen, Paisley, United Kingdom) in a 1:800 dilution and goat anti-rat Alexa Fluor 488 (Invitrogen, Paisley, United Kingdom) in a 1:150 dilution. For ease of reference, working dilutions for anti-Iba-1 and anti-MHC-II and their corresponding secondary antibody are omitted for simplicity.
For the study of the expression of CD68 (which recognizes a single-chain heavily glycosylated protein of 90 to $110 \mathrm{kD}$ that is expressed on the lysosomal membrane of active phagocytic cells) in retinal microglia, retinas of naïve $(\mathrm{n}=3)$ and OHT eyes $(\mathrm{n}=3)$, and their contralateral eyes $(n=3)$ were double immunostained with antiIba1 and anti-CD68. The working dilution was 1:40 for CD68 rat anti-mouse (AbD Serotec, Oxford, United Kingdom). Binding sites of anti-CD68 were visualized after two days of incubation with the secondary antibody goat anti-rat Alexa Fluor 488 (Invitrogen, Paisley, United Kingdom) in a 1:150 dilution.

For the study of the expression of CD86 (which recognizes a co-stimulatory molecule) on retinal microglia, retinas of naïve $(\mathrm{n}=3)$ and OHT eyes $(\mathrm{n}=3)$, and their contralateral eyes $(n=3)$ were double immunostained with anti-Iba1 and anti-CD86. The working dilution was 1:25 for rat anti-mouse CD86 (BD Pharmigen Europe, Madrid, Spain). Binding sites of anti-CD86 were visualized after two days of incubation with the secondary antibody donkey anti-rat Alexa Fluor 488 (Invitrogen, Paisley, United Kingdom) in a 1:300 dilution.

For the study of the expression of Ym1 (which recognizes a protein from the lectin family synthesized and secreted by alternatively activated macrophages during inflammation) on retinal microglia, retinas of naïve $(\mathrm{n}=3)$ and OHT eyes, $(n=3)$, and their contralateral eyes $(n=3)$ were double immunostained with anti-MHC class II (eBioscience; San Diego, California, United States) and anti-Ym1. The working dilution was 1:75 for rabbit antiYm1 (StemCell Technologies, Grenoble, France). Binding sites of anti-Ym1 were visualized after two days of incubation with the secondary antibody donkey anti-rabbit Alexa Fluor 594 (Invitrogen, Paisley, United Kingdom) in a 1:800 dilution.

In all instances, a negative control was performed to demonstrate that the secondary antibody reacted only with its respective primary antibody. This control was made by eliminating the primary antibody and replacing it with an antibody buffer. In addition to identifying the contribution of the endogenous fluorescence to the observed label, a tissue sample was incubated in all the buffers and detergents used in the experiment but without antibodies [51].

Retinas were analyzed and photographed with the ApoTome device (Carl Zeiss, Munich, Germany) and with a digital high-resolution camera (Cool- SNAP Photometrics, Tucson, Arizona, United States) coupled to a fluorescence microscope (Axioplan 2 Imaging Microscope Carl Zeiss, Munich, Germany). The microscope was equipped with appropriate filters for fluorescence-emission spectra of Alexa fluor 488 (Filter set 10, Zeiss), Alexa fluor 594 (Filter set 64, Zeiss) and DyLight 405 (Filter set 49, Zeiss). The ApoTome uses the 'structured illumination' method 
that enables conventional microscopy to create optical sections through the specimen and thereby improve the contrast and resolution along the optical axis. Z-stacks acquired under the $\times 63$ objective were analyzed in Axiovision version 4.2 (Carl Zeiss, Munich, Germany) with Inside4D module in order to perform cut-view analysis. A cut-view is a software-generated reconstruction of the $\mathrm{xz}$ and $\mathrm{yz}$ planes of the $\mathrm{z}$-stack, allowing visualization through the depth of the acquired z-stack.

Adobe Photoshop CS3 Extended 10.0 (Adobe Systems, Inc., San Jose, California, United States) was used for figure preparation.

\section{Retinal analysis}

To determine the effect of OHT on Iba-1+ cells, we quantified these cells in the retinal whole-mounts of naïve $(n=6)$, contralateral $(n=9)$, and OHT eyes $(n=9)$. Twenty-four equivalent areas of the retina were consistently selected for each retinal whole-mount in both the vertical and horizontal meridians which cross the optic nerve (Figure 1A). Each complete meridian selected in the retinal whole-mount was analyzed using the motorized stage of the microscope to scan their whole extension along the $\mathrm{X}-\mathrm{Y}$ axis, respectively. Thus, all subsequent fields analyzed were contiguous and were examined systematically to ensure that no portion of the retinal whole-mount would be omitted or duplicated. Additionally, due to labeled Iba-1+ cells lying outside the immediate focal plane, we analyzed the whole preparation along the $\mathrm{Z}$ axis. These procedures were made at $20 \times$, giving an area of $0.1502 \mathrm{~mm}^{2}$ per field analyzed.

The quantification method used depended on the cell number and cell-distribution characteristics of each retinal layer. The Interactive Measurement, a manual counting tool included in the AxioVision Release 4.8.2 computer program (Zeiss, Germany) in association with the ApoTome device coupled to the fluorescence microscope, was used for cell counting in the OS. Quantitative analysis of Iba-1+ somas was limited to those fully contained in the imaging space taken. For the plexiform layers and NFL-GCL, we created a reliable and quick algorithm of segmentation and control of distances developed in MATLAB (high-level technical computing language that can be used for image processing) [52]. In the IPL and OPL, Iba-1+ cells were distributed throughout the retina in a mosaic-like fashion without overlap between neighboring cells. This feature allows the algorithms to automatically determine the number of Iba-1+ cells. By contrast, in the NFL-GCL cell separation and distribution did not fulfill the criteria for automatic individual cell-counting, and therefore we quantified the area of the retina occupied by Iba- $1+$ cells (Iba1-RA) in this retinal layer $[36,53]$. For this purpose, images of the NFL-GCL were thus processed with a threshold tool in MATLAB. Thresholding defines a range of gray-scale values found on the pixels of objects of interest, differentiating them from other parts of the image based on the image's gray scale. By using the pixel value information, we quantified the Iba1-RA in each photograph selected.

In a second step to further evaluate the effect of OHT in the Iba-1+ cell population, we analyzed in each eye the total arbor area of Iba-1+ cells $\left(\mu \mathrm{m}^{2}\right)$ in four equivalent retinal areas of the selected ones used for cellquantification analysis. The same analysis was performed in IPL and outer plexiform layer (OPL) due to the regular mosaic-like distribution of Iba-1+ cell in the plexiform layers in order to facilitate the measuring process. For this, we proceeded with a computer-assisted morphometric analysis. A polygon was drawn manually by connecting the distal-most tips of the Iba-1+ cell processes (Figure 1B) using the Interactive Measurement, tool of AxioVision (Zeiss, Germany), in association with the ApoTome device coupled to the fluorescence microscope.
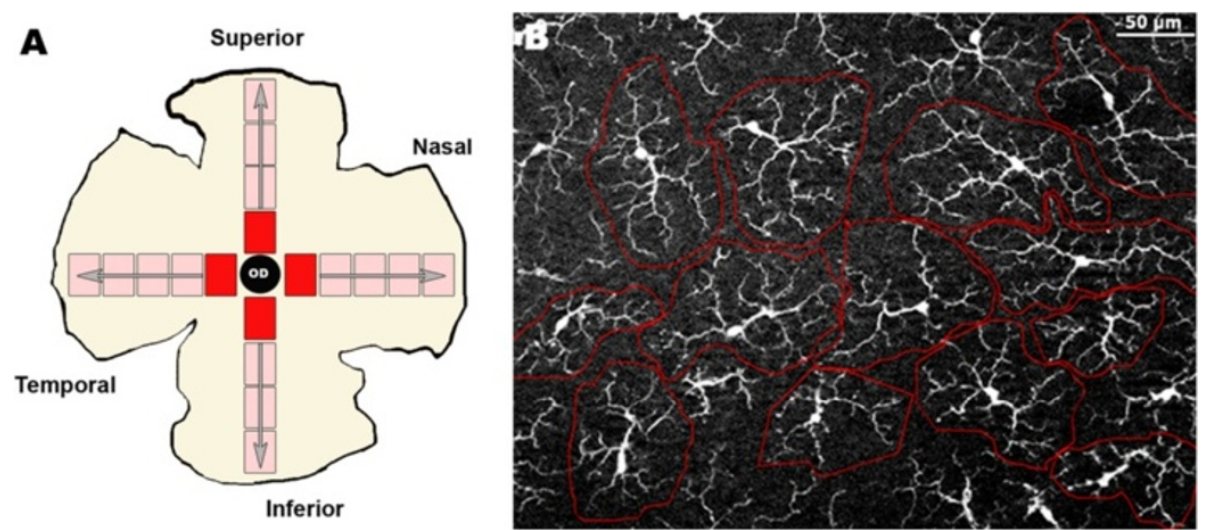

Figure 1 Retinal whole-mount. A: areas of retina selected for quantitative analysis of Iba-1+ cells. B: photomicrograph illustrating the method used for arbor-area quantification of Iba-1+ cells. A polygon was drawn manually by connecting the distal-most tips of the lba-1+ cell processes. 

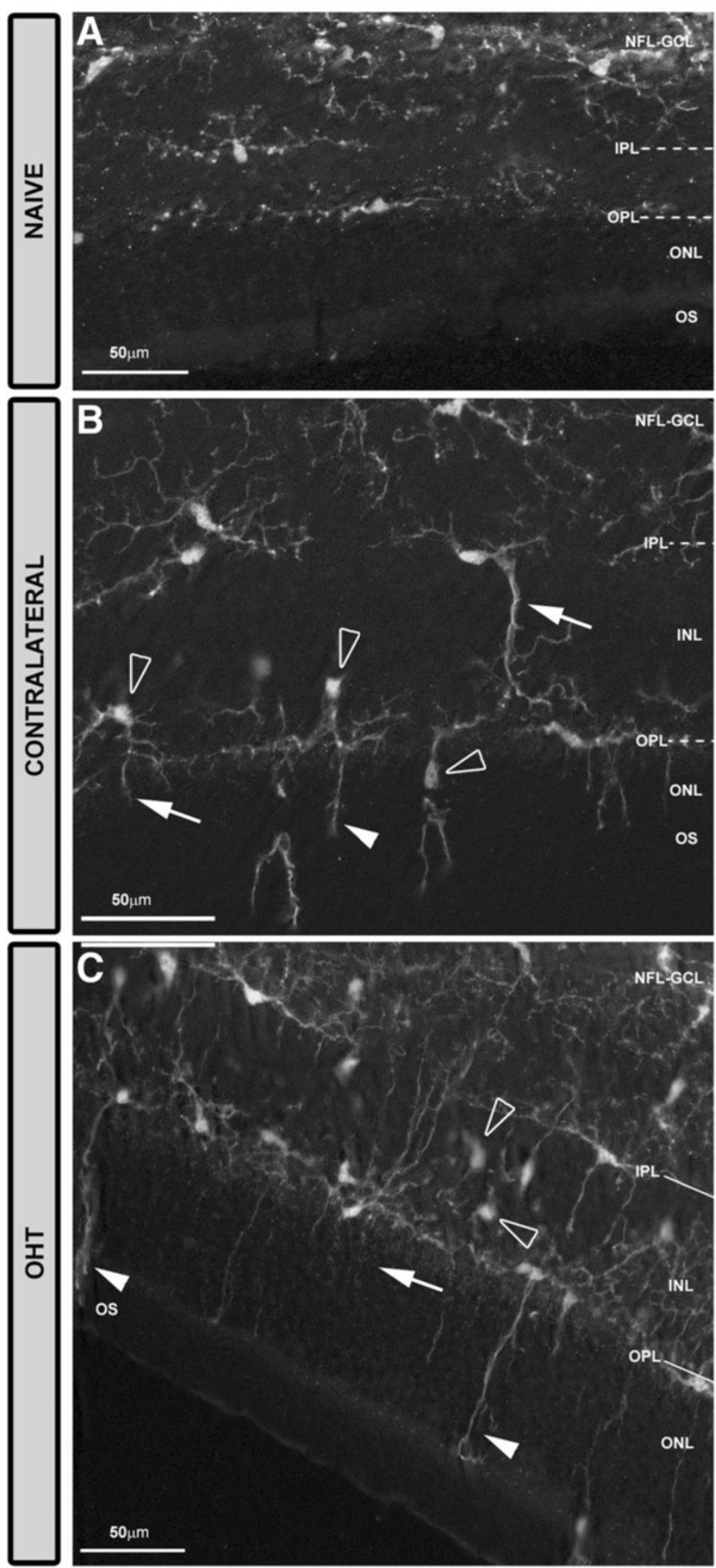

Figure $\mathbf{2}$ (See legend on next page.) 
(See figure on previous page.)

Figure 2 Distribution of Iba-1+ cells in the retinal whole-mounts after 15 days of unilateral laser-induced OHT. Iba-1 immunostaining. Retinal whole-mount. The pressure produced by the cover slip on the whole-mount caused a retinal-like section effect on one edge of the tissue that revealed that: in naïve eyes (A) Iba-1+ cells were distributed in the NFL-GCL, IPL and OPL. Somas and processes of ramified Iba-1+ cells ran parallel to the retinal surface. In contralateral eyes (B) somas (blank arrowhead) and processes (arrow) displaced to and extended to the INL and ONL, respectively. In the OPL the long processes of Iba-1+ cells reached the OS (arrowhead). In OHT eyes (C) the features observed in contralateral eyes (B) were more intense. (INL: inner nuclear layer; IPL inner plexiform layer; NFL-GCL: nerve fiber layer-ganglion cell layer; OHT: ocular hypertension; ONL: outer nuclear layer; OPL: outer plexiform layer; OS: photoreceptor outer segment).

\section{Statistical analysis}

Data for the statistical analysis were introduced and processed in a SPSS 19.0 (comprehensive statistical software; SPSS Inc ${ }^{\odot}$, Armonk, New York, United States). Data are shown as mean \pm SD. Statistical analyses were performed with $t$-test to identify differences among of the OHT, contralateral and naïve eyes as follows: i) IOP values; ii) Iba-1+ cell number in the photoreceptor outer segment (OS), OPL and IPL; iii) Iba1-RA in the NFL-GCL; and iv) arbor area of the Iba-1+ cells in the OPL and IPL. Differences were considered significant when $P<0.05$.

\section{Results}

\section{Laser-induced ocular hypertension}

The IOP values of OHT eyes $(29.55 \pm 4.44 \mathrm{mmHg})$ significantly differed from naïve values $(16.16 \pm 3.11 \mathrm{mmHg}$; $P<0.001$, one way analysis of variance (ANOVA) with Bonferroni method) and contralateral values (15.47 \pm 1.57 mmHg; $P<0.001$, ANOVA with Bonferroni method). No significant differences were found between contralateral and naïve eyes.

\section{Iba-1+ retinal cells: morphology and distribution}

In the study groups, Iba-1+ cells were evenly distributed throughout the retina from the central zone to the periphery. They were distributed in different retinal layers: NFL-GCL, IPL, OPL, and OS (Figure 2).

Most Iba-1+ cells within the naïve retina had a ramified morphology. Overall, they had a small ovoid or triangular soma from which three to four primary processes sprouted and then divided dichotomously into secondary ones. Ramified Iba-1+ cells were examined in the NFLGCL, IPL, and OPL and their somas and processes ran parallel to the retinal surface. In the plexiform layers, ramified Iba-1+ cells were distributed throughout the retina in a mosaic-like fashion without overlapping between neighboring cells. Specific features of the ramified Iba-1+ cells as well as the presence of other morphological types varied depending on the retinal layer analyzed and on the study groups (naïve, contralateral, and OHT eyes) as shown in Figure 3.

\section{Iba-1+ cells in the NFL-GCL}

In naïve eyes, two morphological types of Iba-1+ cells were observed in the NFL-GCL: ramified (Figures 3A, 4A,B) and perivascular (Figures 3A, 4B). In both instances, they are related to the blood vessels. Most Iba- $1+$ cells had a ramified morphology, varicose processes, and somas located on the retinal vessels and in the intervascular space. From both primary and secondary processes sprouted thin processes that on occasions ended as bulbous-tips (Figures 3A, 4A). Ramified Iba-1+ cells ran parallel to the retinal surface and in some instances, processes penetrating the layer perpendicularly were observed. Perivascular Iba-1+ cells showed elongated morphology and thick somas and processes. These cells were found in the vessel walls (Figures $3 \mathrm{~A}, 4 \mathrm{~B}$ ), specifically on the surface of the retinal large vessels, in the vicinity of the optic nerve, and in the collecting tube venule of the peripheral retina.

In contralateral eyes and OHT eyes the two morphological types of Iba-1+ cells described above showed a retraction of the cellular processes in comparison with naive eyes (Figures 3B,C, 4C-H). In addition, scarce Iba-1+ cells with an ameboid morphology were observed in this layer in contralateral eyes (Figures 3B, 4D inset) and were more frequently found in OHT eyes (Figures 3C, 4G). Notably, two additional morphological types of Iba-1+ cells were observed only in OHT eyes: i) rounded cells (Figures 3C, 4G) and ii) rod-like cells (Figures $3 \mathrm{C}, 4 \mathrm{H}$ ). Rounded cells were found adjacent to the major retinal vessels (Figure 5F) or in the neural parenchyma and were observed mainly in the vicinity of the optic disk (Figure 5E) and in the periphery of the retina. In some instances, the processes of ramified Iba-1+ cells surrounded the rounded Iba-1+ cells (Figure 5C). These cells showed a less intense Iba-1+ immunolabeling than did ameboid cells (Figure 4G). Rod-like cells had elongated cell bodies and two processes prominently projected from each pole which were aligned end-to-end, coupling to form trains associated with axons and not related to retinal vessels (Figure $4 \mathrm{H}$ ).

\section{Iba-1+ cells in the IPL}

In the IPL of naïve eyes, two morphological types of Iba$1+$ cells were distinguished: ramified and dendritic-like cells (Figures 3D, 6B).

Most Iba-1+ cells in the IPL were ramified and their somas were located next to the GCL or inner nuclear layer (INL). In comparison with ramified cells in the NFL-GCL, they had fewer thin processes emerging from 


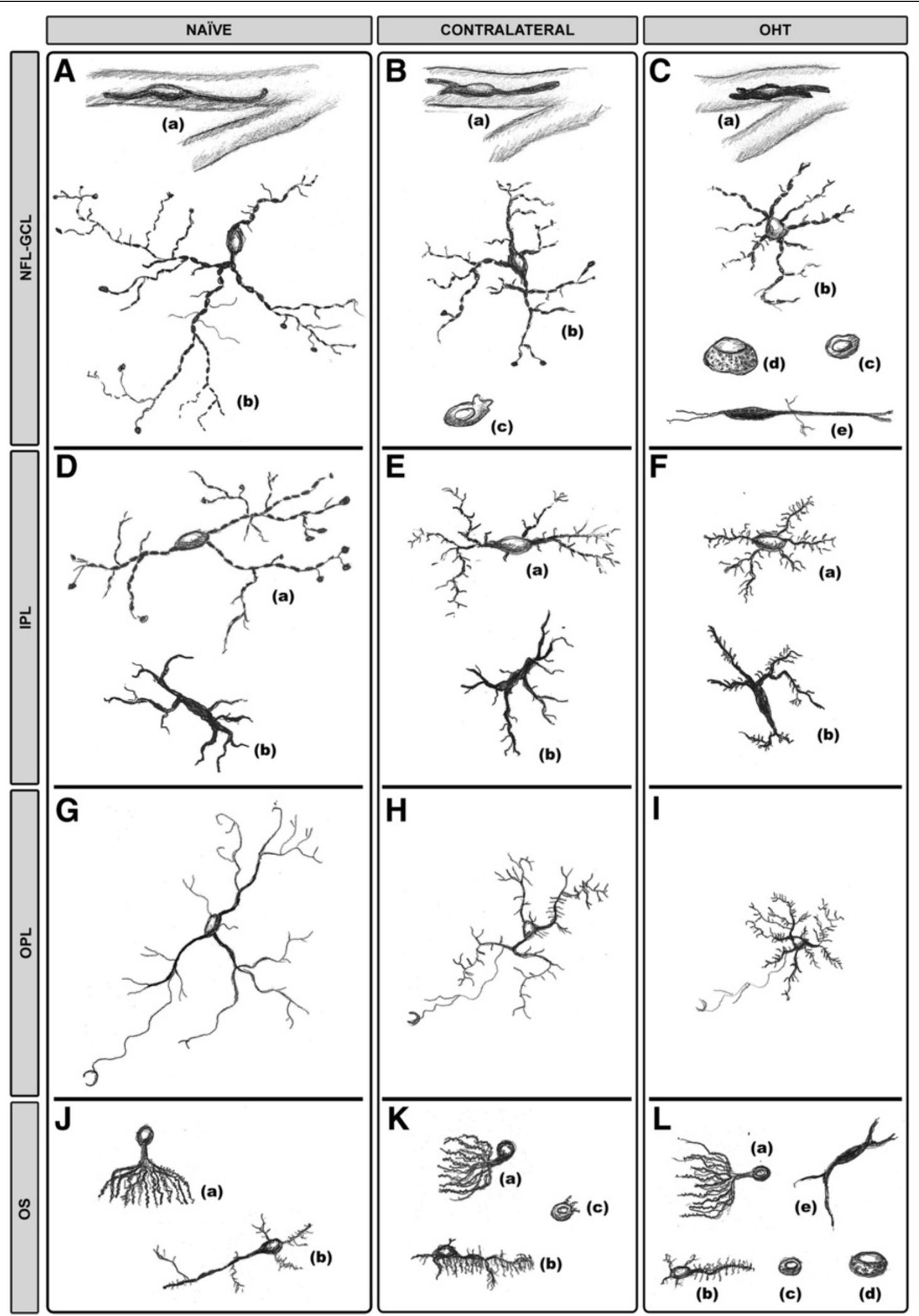

Figure 3 (See legend on next page.) 
(See figure on previous page.)

Figure $\mathbf{3}$ Morphological changes in Iba-1+ cells. The idealized schematic drawing illustrates the morphological types of Iba-1+ cells in the different retinal layers in naïve $(\mathbf{A}, \mathbf{D}, \mathbf{G}, \mathbf{J})$, contralateral $(\mathbf{B}, \mathbf{E}, \mathbf{H}, \mathbf{K})$ and $\mathrm{OHT}$ eyes $(\mathbf{C}, \mathbf{F}, \mathbf{I}, \mathbf{L})$. Proportions between cell sizes were established taking into account the scale value of the microphotographs. In NFL-GCL (A-C), both in contralateral (B) and in OHT eyes (C), perivascular cells (a) and ramified cells (b) showed a retraction of their cellular processes in comparison with naïve eyes (A). Ameboid cells (c), absent from naïve eyes (A), were observed in contralateral (B) and in OHT eyes (C). Only in OHT eyes (C) were two additional morphological types of Iba- $1+$ cells observed: rounded cells (d) and rod-like cells (e). In the IPL (D-F) ramified cells (a) and dendritic-like cells (b) exhibited signs of activation (process retraction in (a) and increased secondary and higher-order processes $(a, b))$ in contralateral (E) and in OHT eyes (F). In the OPL (G-I) ramified cell processes were retracted and were increased in contralateral $\mathbf{( H )}$ and in OHT eyes $\mathbf{( I )}$ in comparison with naïve eyes $(\mathbf{G})$. In the OS (J-L), cell orientation of type 1 OS Iba-1+ cells (a) changed from perpendicular in naïve eyes $(\mathbf{J})$ to parallel to the retinal surface in contralateral $(\mathbf{K})$ and in OHT eyes (L). Processes of type 2 OS Iba-1+ cells (b) had a retraction of their processes and a hairy appearance in contralateral (K) and in OHT eyes (L). Ameboid cells (c) were observed in contralateral (K) and OHT eyes (L) but not in naïve eyes (J). Only in OHT eyes (L) appeared rounded Iba-1+ cells (d) and cells with a dendritic-like appearance (e) in the OS. (NFL-GCL: nerve fiber layer-ganglion cell layer; IPL: inner plexiform layer; OHT: ocular hypertension; OPL: outer plexiform layer; OS: photoreceptor outer segment).

primary and secondary processes, which gave them a less ramified appearance (Figures 3D, 6B). Processes were varicose and most of them ended as bulbous-tips (Figures 3D, $6 \mathrm{~B})$. Some processes reached both the GCL and INL. In addition to the cells described above, a few Iba- $1+$ cells had thick somas and two to four thick primary processes and short, thick secondary ones, giving the cell a dendritic-like appearance (Figures 3D, 6C). Dendriticlike cells ran parallel to the retinal surface and were located in the juxtapapillary area and in the vicinity of the collecting tube venule in the peripheral retina.

In comparison with naïve eyes, ramified Iba-1+ cells in the IPL of contralateral eyes and OHT eyes formed a denser cellular mosaic (Figure 6A,D,G) and exhibited: i) a retraction of the cellular processes (Figures 3E,F, 6E, $\mathrm{H}$ ); ii) a disappearance of the bulbous-tip (Figures 3E,F, $6 \mathrm{E}, \mathrm{H})$; iii) numerous thin and short secondary and superior order processes which gave the cells a fuzzy appearance; iv) displacement of some somas into the INL and GCL (Figure 2B,C); and v) numerous perpendicular processes that penetrated adjoining layers (Figure 2B,C). Dendritic-like Iba-1+ cells in contralateral and OHT eyes had numerous thin and short secondary and superior order processes (Figures 3E,F, 6F,I). In both cellular types, the aforementioned signs of cell activation were more pronounced in OHT eyes (Figures 3F, 6G,H,I) than in contralateral eyes (Figures 3E, 6D,E,F).

\section{Iba-1+ retinal cells in the OPL}

In the OPL of naïve, contralateral, and OHT eyes, only ramified Iba-1+ cells were detected. These formed a mosaic-like pattern denser than in the IPL (Figure 7).

In naïve eyes (Figures 3G, 7A-C), a specific feature of these cells was the presence of numerous thin processes sprouting from the soma and the primary and secondary processes. Some processes extended to the INL and ONL. On occasions, a long process extending from the soma ran across the ONL into the OS (Figure 7C) where it ended in a goblet-like shape (Figure 3G).
In contralateral and OHT eyes as compared with naïve eyes, ramified Iba-1+ cells in the OPL showed: i) retraction of processes (Figures 3H,I,7D,E,G,H); ii) numerous thin and short secondary and superior order processes (Figures 3H,I, 7E,F,H,I); iii) a displacement of the some somas to the INL and ONL (Figure 2B,C); iv) greater number of processes reaching the $O S$ (Figure 7F,I) and; v) a denser cellular mosaic (Figure 7D,E, $\mathrm{G}, \mathrm{H})$. All these characteristics were more pronounced in the OHT eyes (Figures 3I, 7G-I) than in the contralateral eyes (Figures 3H, 7D-F).

\section{Iba-1+ retinal cells in the OS}

In three groups of eyes studied, Iba-1+ cells in the OS were unevenly distributed.

In the naïve eyes, two main morphological types of Iba$1+$ cells were observed depending on their morphology and location: i) cells with ovoid somas located near or inside the ONL and numerous processes emerging from the same point of the soma, like the roots of a tree (Type 1OS) (Figures 3J, 8A). These processes extended across the thickness of the OS, perpendicularly to the retinal surface (Figure 8A). This morphological type was the predominant one in the OS; and ii) cells with ovoid somas located near the retinal pigment epithelium (RPE) and one thick primary process running parallel to the retinal surface. Sparse, thin, and short processes sprouted from the soma and the primary process (Type 2- OS) (Figures 3J, 8B). These cells were more frequently detected in the vicinity of the ora serrate.

In comparison with naïve eyes, the morphology and arrangement of the two cell types described above varied in contralateral and OHT eyes. Type 1 OS Iba-1+ cells were displaced to the vicinity of RPE and formed groups that were randomly distributed throughout the layer. All the cells in a group had their processes oriented in the same direction (Figure $8 \mathrm{C}, \mathrm{E}$ ). In contralateral eyes, the orientation of the processes began to change from perpendicular to parallel to the retinal surface (Figures $3 \mathrm{~K}$, $8 \mathrm{C})$. In OHT eyes, both the somas and the processes 


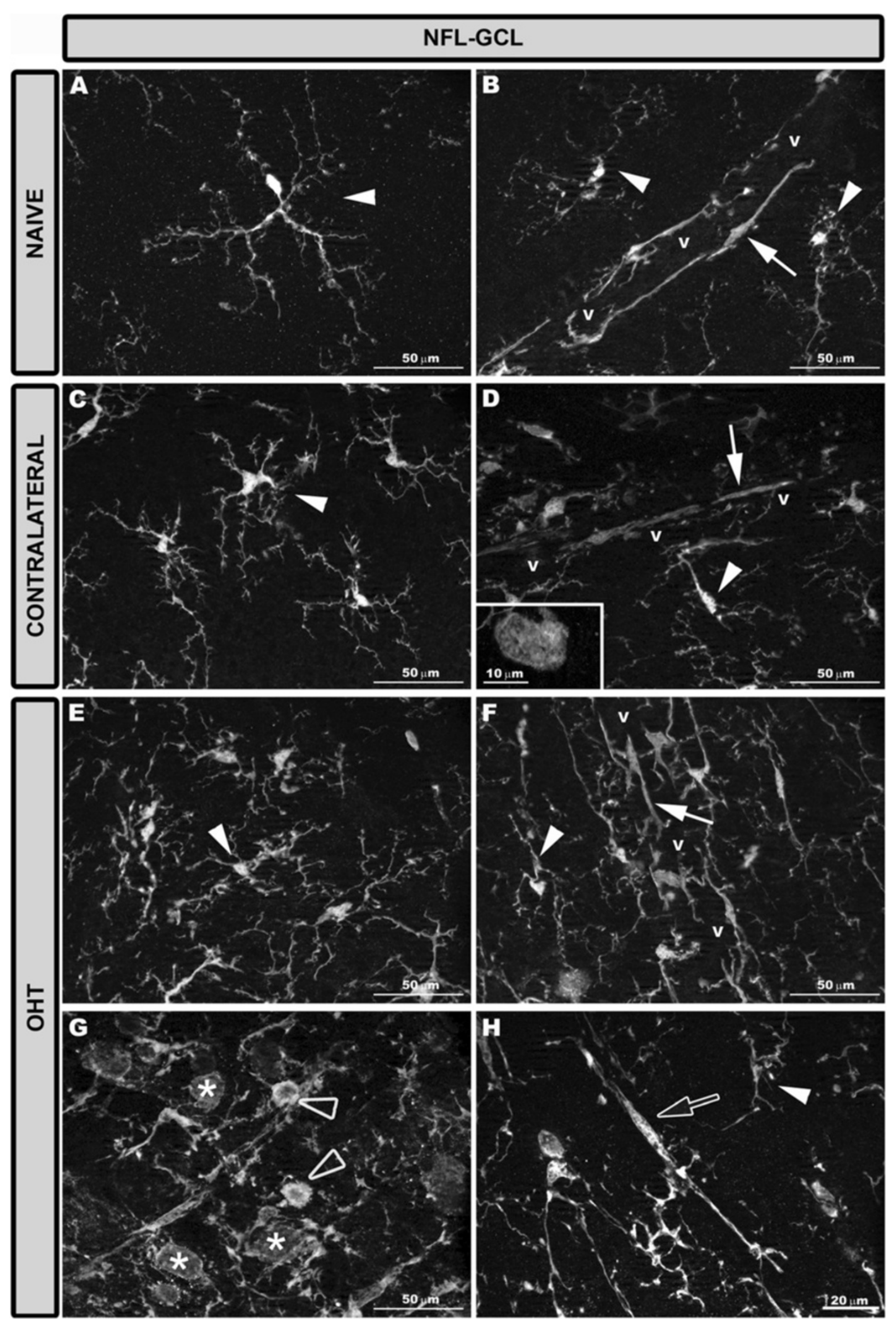

Figure 4 (See legend on next page.) 
(See figure on previous page.)

Figure 4 lba-1+ cells in the NFL-GCL after 15 days of unilateral laser-induced OHT. Iba-1 immunostaining. Retinal whole-mount. In naive eyes (A, B) there were ramified Iba-1+ cells (arrowhead) with varicose processes and perivascular Iba-1+ cells (arrow) with elongated morphology and thick processes. Both in contralateral eyes (C, D) and in OHT eyes (E-H) ramified Iba-1+ cells (arrowhead in C-F, H) and perivascular Iba-1+ cells (arrow in D, F) showed a retraction of the cellular processes. Scarce ameboid lba-1+ cells were detected in contralateral eyes (D inset) and more frequently in OHT eyes (blank arrowhead in G). Only in OHT eyes were two additional morphological types of Iba-1+ cells discerned (G, H): rounded cells (asterisk in $\mathrm{G}$ ) and rod-like cells with elongated cell bodies and two processes prominently projecting from each pole (blank arrow in $\mathbf{H}$ ). (NFL-GCL: nerve fiber layer-ganglion cell layer; OHT: ocular hypertension; v: retinal vessel).

were clearly arranged parallel to the retinal surface (Figures 3L, 8E). In contralateral and OHT eyes the processes of type 2 OS Iba-1+ cells had a retraction of their processes and a hairy appearance due to abundant thin and short processes that sprouted from the soma and main processes (Figures 3K,L, 8D,F).

As in the NFL-GCL, ameboid Iba-1+ cells were detected in contralateral (Figures 3K, 8D inset) and OHT eyes (Figures $3 \mathrm{~L}, 8 \mathrm{H}$ ) but were more frequently found in the OHT eyes. Also, two more morphological types of Iba-1+ cells were observed only in OHT eyes: i) cells with a dendritic-like appearance (Figures 3L, 8G), similar to IPL and, ii) rounded Iba-1+ cells (Figures $3 \mathrm{~L}, 8 \mathrm{H}$ ), which were scarce, located in the retinal periphery and showing a patchy distribution.

\section{Activation markers in Iba-1+ retinal cells: MHC-II, CD68, CD86, and Ym1 \\ Age-matched control (naive)}

Overall, Iba-1+ cells in naïve retinas had a weak constitutive MHC-II expression (Figure 9A,D,G,J; Additional file 1) except for the dendritic-like cells in the IPL, which had an intense constitutive MHC-II expression (Figure 9D). With respect to $\mathrm{CD} 68$, the immunostaining varied depending on the retinal layer analyzed. Thus, a punctate CD68 immunostaining was scarcely found in the soma of few Iba-1+ cells in the NFL-GCL and plexiform layers (Additional file 1). However, in the OS patches of CD68, immunostaining was found in most type 1 OS cells but only in some type 2 OS cells (Figure 10A,B; Additional file 1). No immunostaining for CD86 or Ym1 was found in naïve eyes (Additional file 1).

\section{Contralateral and $\mathrm{OHT}$ eyes}

Both in contralateral (Figure 9B,E,H,K) and OHT eyes (Figure 9C,F,I,L), Iba-1+ cells showed upregulation in MHC-II expression in all retinal layers (Additional file 1). In contralateral eyes CD68 immunostaining was similar to naive eyes except for a few ramified Iba-1+ cells in the IPL which had a patchy CD68+ immunostaining instead of the punctate immunostaining observed in naïve eyes (Additional file 1). In addition, ameboid Iba-1+ cells in the NFL-GCL (Figure 5A,B) and OS (Figure 10C,D) in contralateral eyes exhibited intense CD68 immunostaining. CD86 immunostaining was restricted to some ameboid
Iba-1+ cells (Figure 11B,C; Additional file 1). No Ym1+ cells were observed (Additional file 1).

By contrast, in OHT eyes most Iba-1+ cells had CD68 immunostaining in the somas and in some processes that varied from punctate to patchy (Figure 10G,H; Additional file 1). The retinal layer having the greatest CD68 immunostaining was the NFL-GCL and OS, due to ameboid cells (Figure 10E,F, 5C,D), and the intense CD68+ cytoplasm exhibited by rounded Iba-1+ cells (Figures 10E, F, 5C,D,E,F) and some rod-like microglia (Figure 5G,H, Additional file 1). CD68 cytoplasmic staining in rounded Iba-1+ cells had a vacuolated appearance (Figure 5C,D). CD86 immunostaining was detected in ameboid Iba-1+ cells (Figure 11E,F, $\mathrm{H}, \mathrm{I}$ ) and rounded Iba-1+ cells (Figure $11 \mathrm{H}, \mathrm{I}$ ). Ym1 was restricted to few ameboid MHC-II cells in the NFLGCL (Figure 11K,L).

\section{Quantitative analysis of Iba-1+ retinal microglial cells Number of Iba-1+ cells in the IPL, OPL, and OS}

OHT eyes had significantly more Iba-1+ cells in the IPL, OPL, and OS than did contralateral and naïve eyes, both when the comparison was made as the sum of Iba$1+$ cells contained in the three layers (Iba-1+ total number, Figure 12) or when the layers were compared one by one between the study groups (Table 1$)(P<0.001$ in all instances; $t$-test). The Iba- $1+$ total number also significantly increased in contralateral eyes in comparison with naïve eyes $(P<0.05$; unpaired $t$-test; Figure 12$)$. The analysis by layers revealed that the IPL of contralateral eyes had significantly more Iba- $1+$ cells than did naïve eyes $(P<0.05$; unpaired $t$-test) (Table 1$)$. In addition, the comparison between OPL and IPL showed that the number of Iba- $1+$ cells was significantly greater in the OPL in naïve $(P<0.01)$, contralateral $(P<0.001)$ and $\mathrm{OHT}$ eyes $(P<0.001$; paired $t$-test in all instances; Table 1$)$.

\section{Area of the retina occupied by $l b a-1+$ cells (Iba1-RA) in the NFL-GCL}

In the NFL-GCL, the area of the retina occupied by Iba$1(+)$ cells (Iba1-RA) in OHT eyes $(19090.57 \pm 6040.56)$ significantly increased in comparison both to contralateral (4689.97 $\pm 359.47 ; P<0.001$; paired $t$-test) and to naïve eyes (4096.94 \pm 260.97; $P<0.001$; unpaired $t$-test; Figure 13). Notably, Iba1-RA in contralateral eyes was 


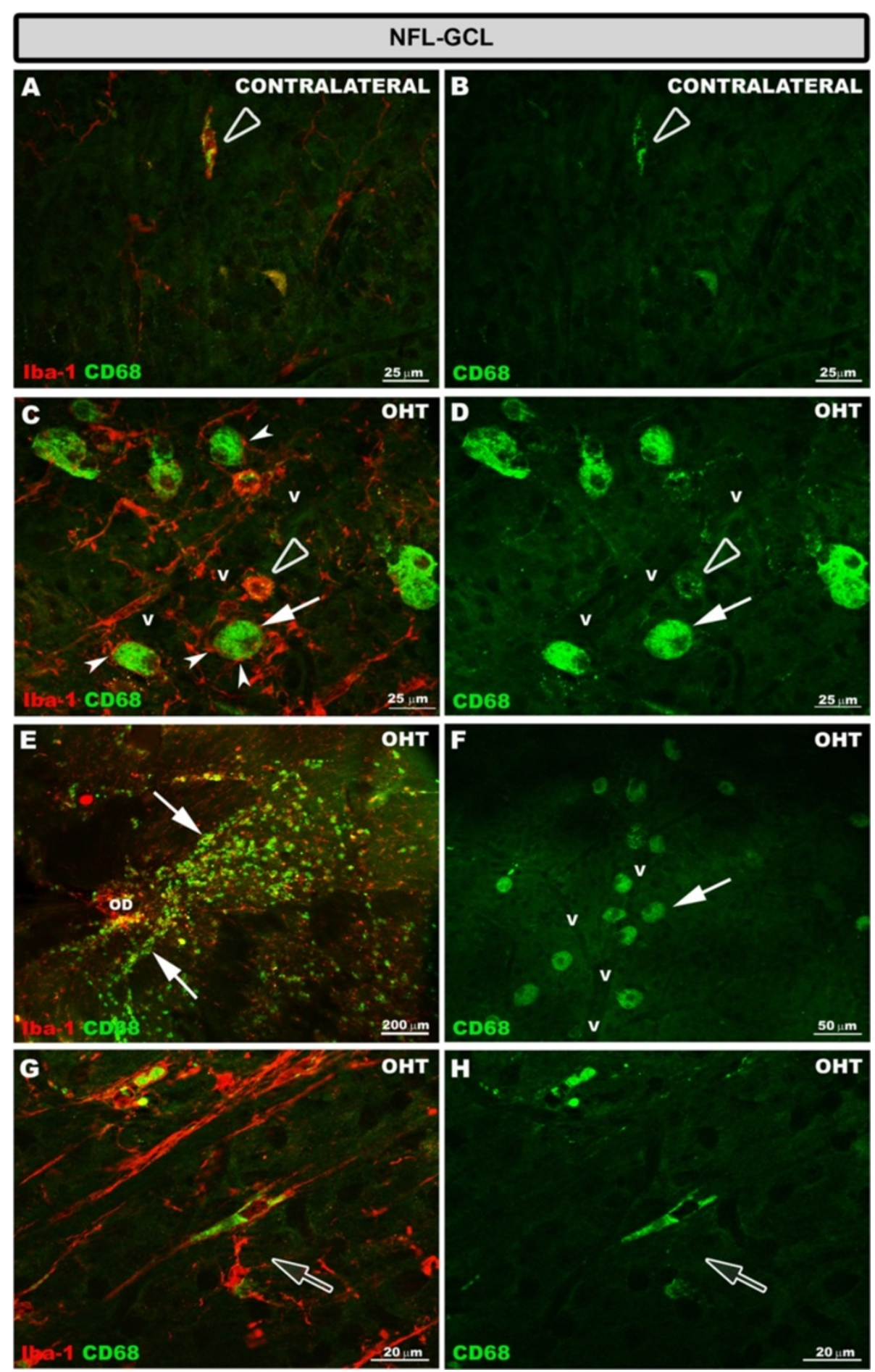

Figure 5 CD68 expression in the NFL-GCL after 15 days of unilateral laser-induced OHT. Double immunostaining: Iba-1/CD68. Retinal whole-mount. In contralateral eyes (A, B) CD68 immunoreaction was detected only in some ameboid lba-1+ cells which exhibited a patchy staining pattern (blank arrowhead). In the retinal whole-mount of OHT eyes (C-H), the greater CD68 immunoreaction was observed in this retinal layer. This was because, in addition to the CD68 immunoreactivity of ameboid Iba-1+ cells (blank arrowhead in C, D), rounded Iba-1+ cells (arrow in $\mathbf{C - F}$ ) and some rod-like cells (blank arrow in $\mathbf{G}, \mathbf{H}$ ) had intense CD68+ cytoplasmic staining. Rounded Iba-1+ CD68+ cells were adjacent to the retinal vessels $(\mathbf{C}, \mathbf{D}, \mathbf{F})$, being located mainly close to the optic disc $\mathbf{( E )}$ and in the periphery of the retina. In some instances, the processes of ramified Iba-1+ cell surrounded the rounded Iba-1+ cells (arrowhead in C) (NFL-GCL: nerve fiber layer-ganglion cell layer; OD: optic disc; OHT: ocular hypertension; v: retinal blood vessel). 


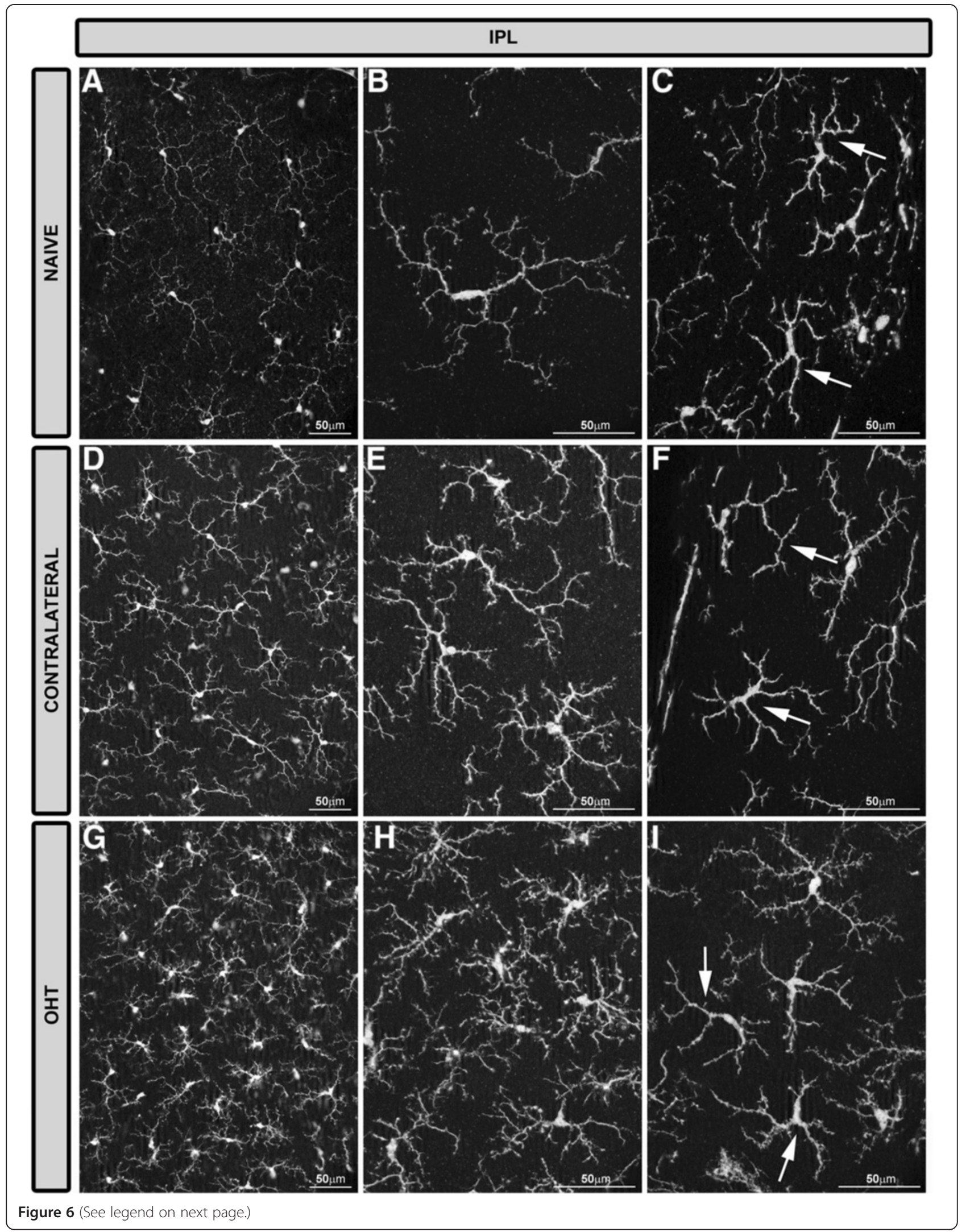


significantly higher than in naïve eyes $(P<0.01$; unpaired $t$-test; Figure 13).

\section{Quantification of the arbor area of the Iba-1+ cells}

The average arbor area of the Iba- $1+$ cells in the IPL and the OPL was significantly reduced in OHT eyes (3492.75 \pm 766.85 for IPL and $3868.80 \pm 477.14$ for OPL) compared to both contralateral $(5473.82 \pm 1023.67$ for IPL and $5545.96 \pm 288.80$ for OPL) and naïve eyes (7031.81 \pm 1238.39 for IPL and $6318.65 \pm 319.17$ for OPL) and in contralateral eyes compared to naïve eyes (Figure 14).

\section{Discussion}

It is currently known that reactive microgliosis associated with retinal damage takes place both in human glaucoma [37-39] as well as in experimental models of OHT [28-34,54]. In the experimental model of OHT used in the present work, we have previously reported that 15 days after laser treatment: i) the microglia of OHT eyes and contralateral untreated eyes had signs of activation [36], and ii) such activation is not observed in eyes receiving laser in the non-draining portion of the sclera (avoiding the aqueous-collecting system) in which IOP values did not differ from those of the naïve group [36]. However, more specific data concerning microglia activation in this model and differences depending on the retinal layer remain unknown. Therefore, in the present study we show a detailed description of multiple signs of activation displayed by the retinal microglia in the different layers of the retina, specifically: morphological changes, cell displacement, increased cell number, upregulation of activation markers (MHC-II, CD68, $\mathrm{CD} 86$, and $\mathrm{Ym} 1$ ) and quantification of the area occupied by Iba- $1+$ cells in the NFL-GCL and the arbor area of Iba- $1+$ cells in the plexiform layers. Our results confirm that 15 days after lasering, the microglia in all retinal layers underwent multiple changes, both in the lasered eye as well as in the contralateral untreated eye.

In the model of laser-induced OHT used in the present work, a substantial increase in the IOP was evident 24 hours after the lasering of the limbal and episcleral veins. This continued for four days and then gradually returned to the basal value after the fifth day, so that one week after lasering, the IOP values in the treated animals were comparable for both eyes [43].

Previous reports on the experimental model of OHT used here showed abnormal electroretinograms [43,44], indicating that cellular involvement extends beyond RGC, supporting findings reported in human glaucoma [55] and in other experimental models of OHT [56-59]. According to this, we observed microglial reactivity in all retinal layers of $\mathrm{OHT}$ and contralateral eyes.

In the normal adult nervous system, microglia are found in a quiescent state characterized by a ramified morphology [60]. When microglia detects an insult, the cell becomes activated (shortening and widening of microglial processes) and can transform into a macrophage-like morphology known as ameboid microglia defined by the absence of the cell processes [14,61-64]. A process of shortening in Iba-1+ cells was noted in all retinal layers in contralateral and OHT eyes and could be consistent with the significant reduction of the Iba-1+ cell-arbor area found in the plexiform layers. Ameboid microglia has been reported in acute processes and neurodegenerative diseases such as Alzheimer's disease and multiple sclerosis [65]. Ameboid microglia is commonly found in the vicinity of lesions in neuroinflammatory disorders [66]. According to this scenario, ameboid CD68+ Iba-1+ cells were found in OHT eyes as well as in contralateral eyes where RGC death has not been reported [43].

In addition to the classical signs of microglial reactivation mentioned above, hyper-ramified microglia, an intermediate activation stage between the resting and reactive forms, has been described [67]. Hyper-ramified microglia have been seen both in the presence of several non-pathological tissue signals [68-70], as well as in cerebral degenerative processes related to axonal damage [71-73]. In the present study, Iba-1+ cells with raised levels of branching were observed in contralateral and OHT eyes in all retinal layers except in the NFL-GCL. In the plexiform layers of OHT eyes, these cell types could be participating in the remodeling of neuronal circuitry by tagging some disrupted synapses for elimination (stripping) in an attempt to prevent the spread of tissue damage [66,74-78]. Notably, in OHT eyes increased microglial branching was absent in the NFLGCL, the only retinal layer having rod-like microglia [35]. As described recently by our group, some processes of rod-like microglia penetrate the underlying IPL accompanying the dendrites of ganglion cells [35]. With this observation, it is tempting to postulate that such a relationship would be consistent with the removal or stripping of the disrupted synaptic contacts attributed to rod-like microglia [75,77]. Also, hyper-ramification could 


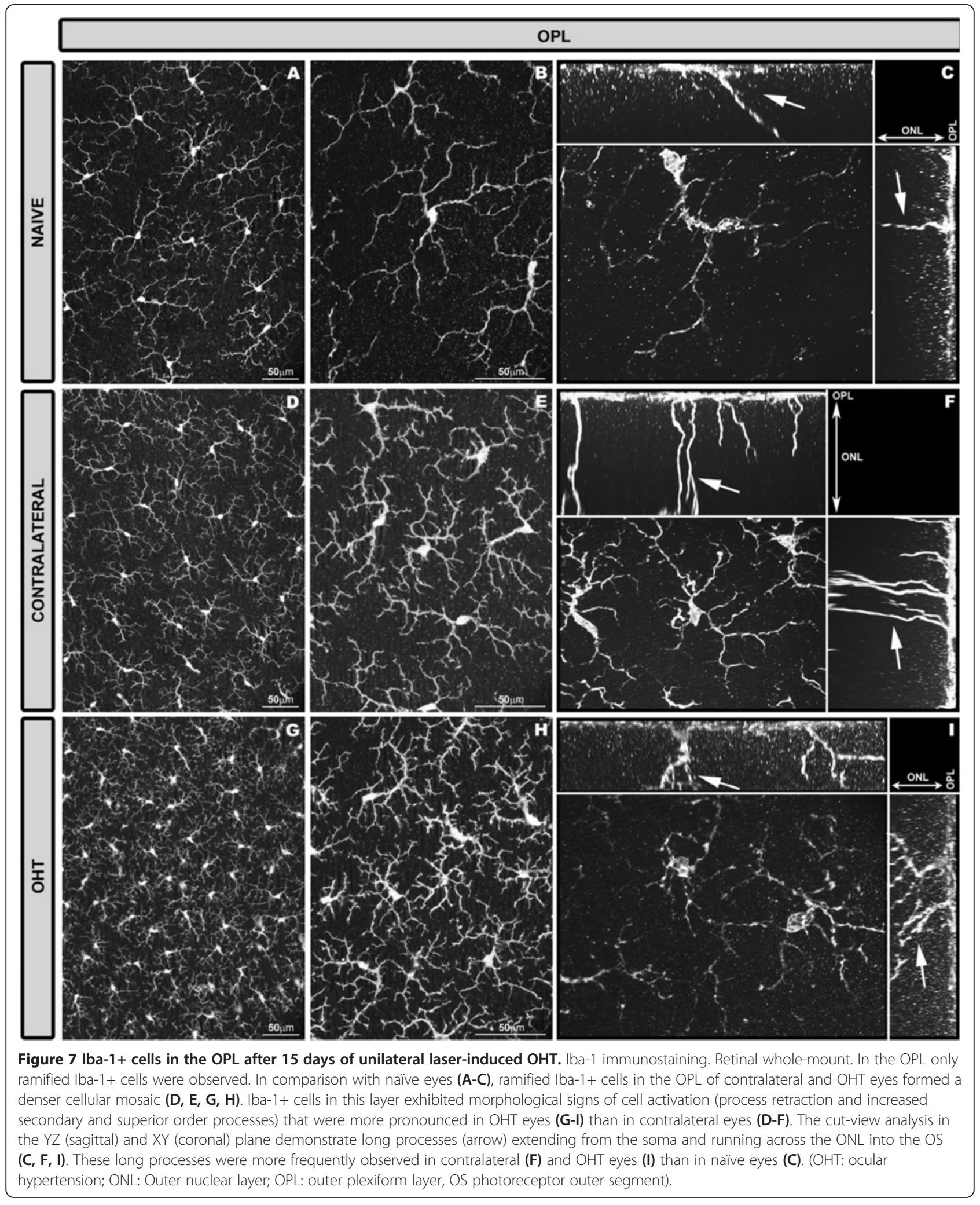

increase the microglial area of surveillance, playing a key role in neuronal survival [68-70]. In contralateral eyes, where neuronal damage has not been reported [43], the presence of Iba-1+ cells with an increased level of branching could reflect the presence of tissue stress signals. 


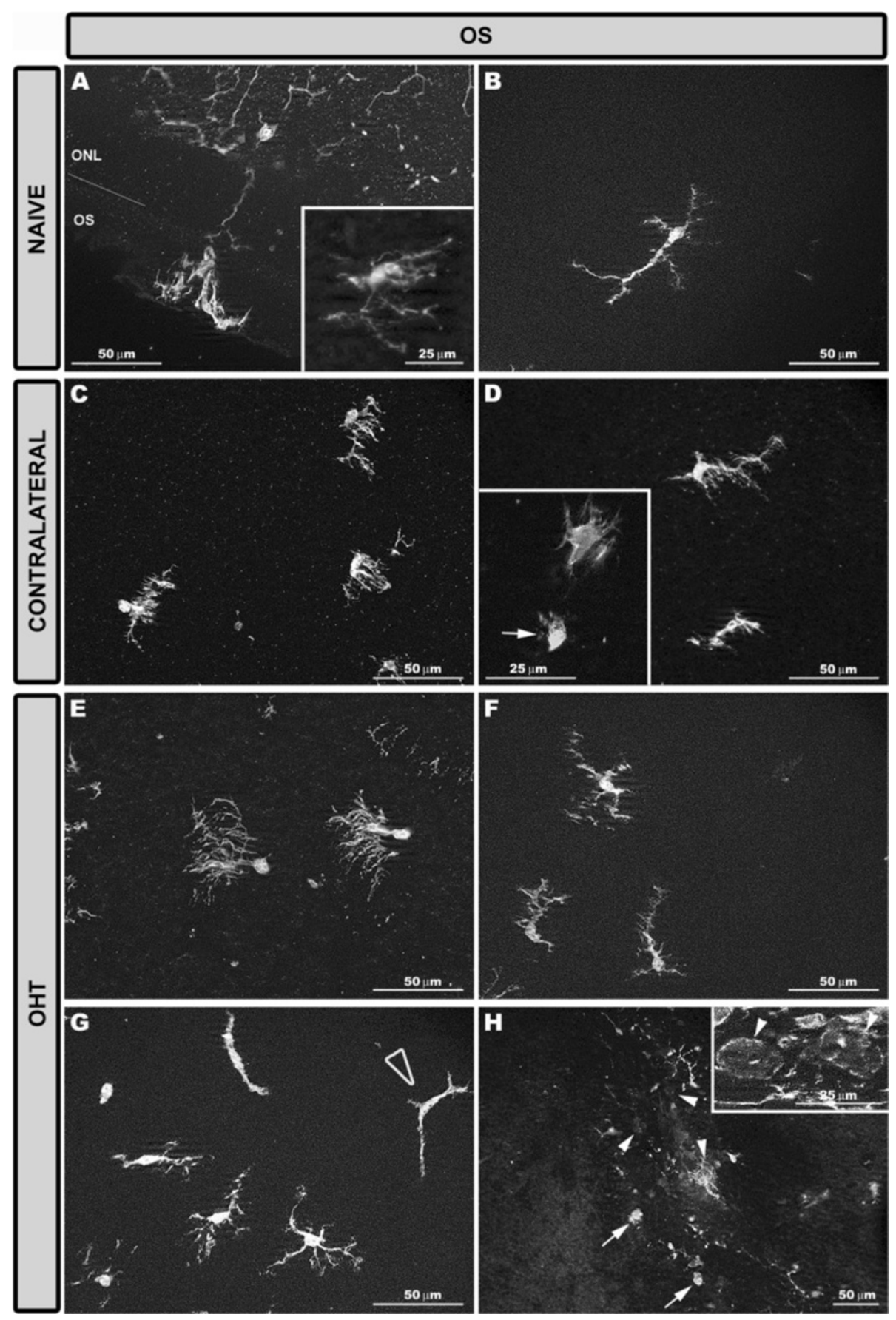

Figure $8 \mathrm{lba}-1+$ cells in the OS after 15 days of unilateral laser-induced OHT. Iba-1 immunostaining. Retinal whole-mount. Type 1 (A, C, E) and type 2 (B, D, F, G) Iba-1+ cells in the OS. The retinal-like section effect produced by the pressure exerted by the cover slip on one edge of the tissue (A) allowed us to observe that in type 1 OS Iba-1+ cells numerous processes emerged from the same point of the soma, like the roots of a tree. In naive eyes these processes extended across the thickness of the OS perpendicularly to the retinal surface. Consequently, soma and processes of type 1 OS cells were located on a different focal plane and therefore both cell structures could not be focused simultaneously during whole-mount analysis (A inset). In contralateral (C) and OHT eyes (E) type 1 OS Iba-1+ cells orientation changed from perpendicular to parallel to the retinal surface. In contralateral (D) and OHT eyes (F) type 2 OS Iba-1+ cells had a retraction of their processes and a hairy appearance. Ameboid Iba-1+ cells were observed in contralateral ( $\mathbf{D}$ inset, arrow) and OHT eyes (arrow in $\mathbf{H}$ ). Only in OHT eyes were two additional morphological types of Iba-1+ cells observed $\mathbf{( G ,} \mathbf{H}$ ): cells with a dendritic-like appearance (blank arrowhead in $\mathrm{G}$ ) and rounded Iba-1+ cells (arrowhead in $\mathbf{H}$ and inset). (OHT: ocular hypertension; ONL: outer nuclear layer; OS: photoreceptor outer segment). 


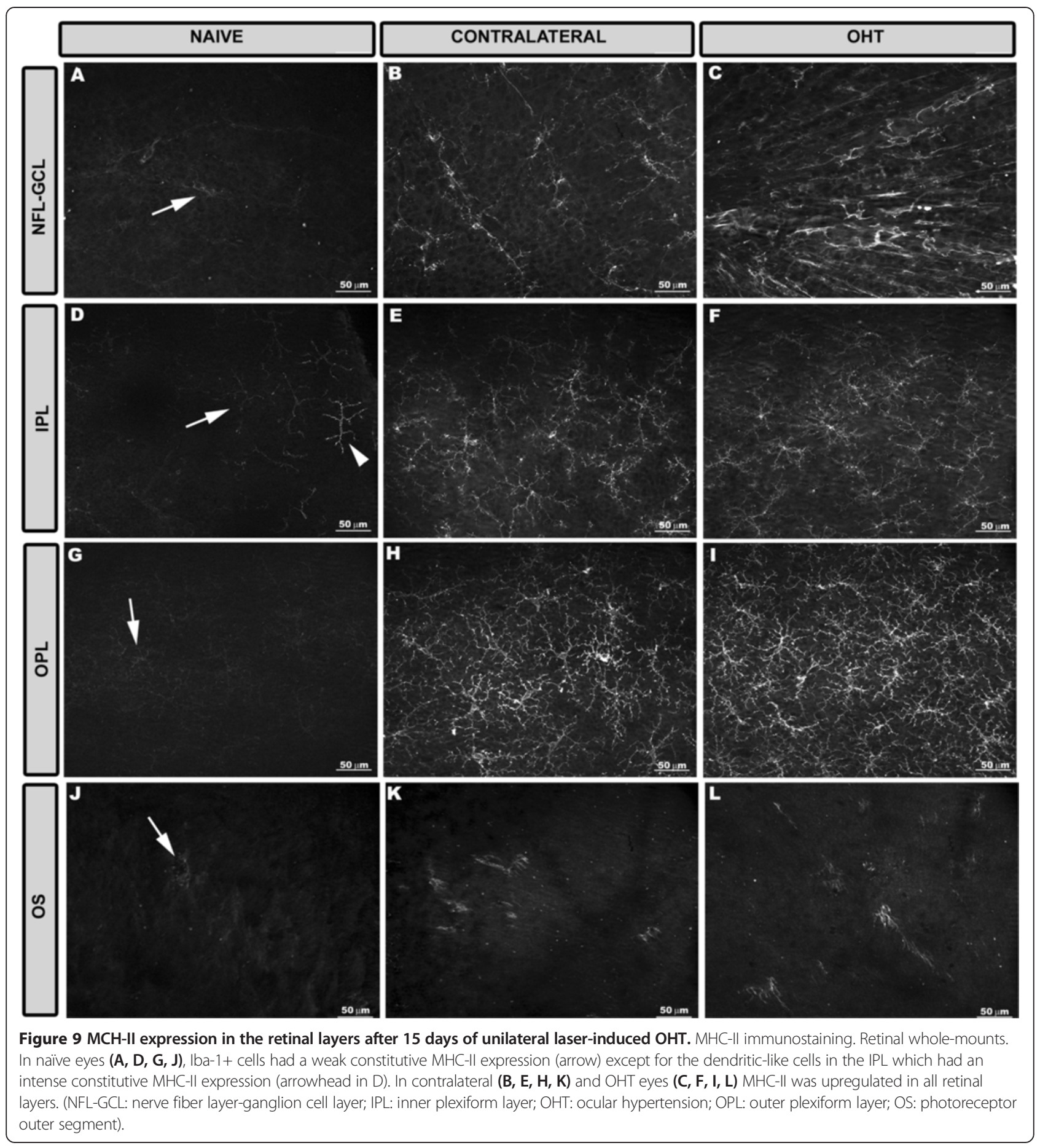

\section{Microglial migration across the retinal parenchyma}

Fifteen days after laser treatment, Iba-1+ cells moved to the nearest nuclear layer in both OHT and contralateral eyes. In experimental glaucoma [12,63], as well as in several retinal diseases [13,17,79-87], microglial activation is associated with cell migration which allows microglia to interact and eliminate damaged or dead neurons $[61,84,88,89]$.
Observations in the present study support the idea of the outer retina being impaired by OHT. In contralateral and OHT eyes: i) type 1 OS cell somas migrated closer to the RPE than in the control group. RPE dysfunction has been associated with migration of the resident microglia from the inner retina to the subretinal space in an attempt to support impaired RPE phagocytic functions [90,91]; and ii) type 1 OS cells reoriented their 


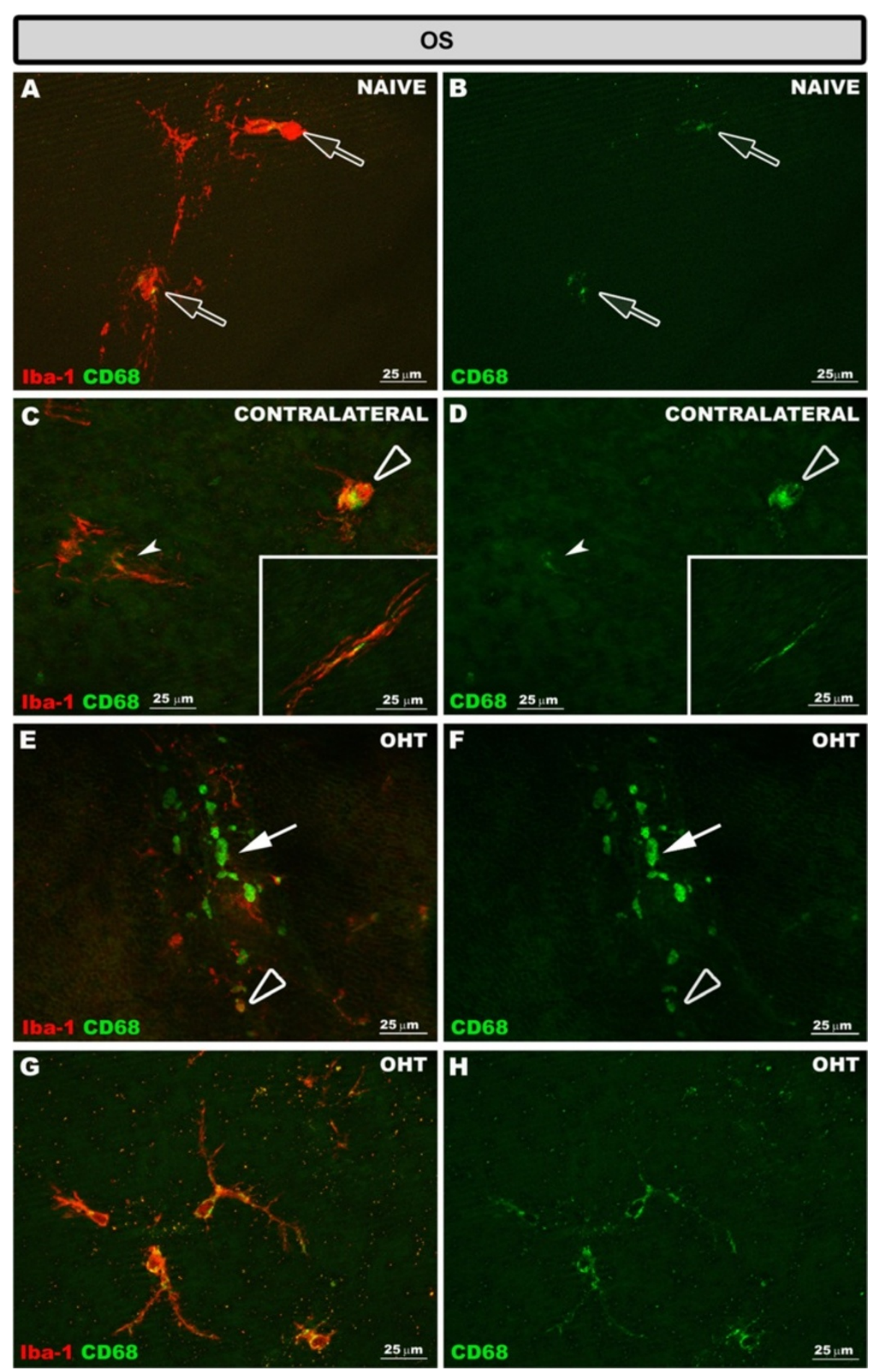

Figure 10 CD68 expression in the OS after 15 days of unilateral laser-induced OHT. Double immunostaining: Iba-1/CD68. Retinal whole-mount. In naïve eyes (A, B) CD68 immunostaining was observed in type 1 OS Iba-1+ cells (blank arrow). In the OS in contralateral eyes (C, D) ameboid Iba-1+ cells (blank arrowhead) had a greater CD68 immunostaining than type 1 OS (arrowhead) and type 2 OS (inset) Iba-1+ cells. In OHT eyes (E-H) CD68 immunostaining in the OS was observed in ameboid Iba-1+ cells (blank arrowhead in $\mathbf{E}, \mathbf{F}$ ), rounded Iba-1+ cells (arrow in $\mathbf{E}, \mathbf{F}$ ) and in the soma and processes of type 2 OS Iba-1+ cells (G, H). (OHT: ocular hypertension; OS: photoreceptor outer segment). 


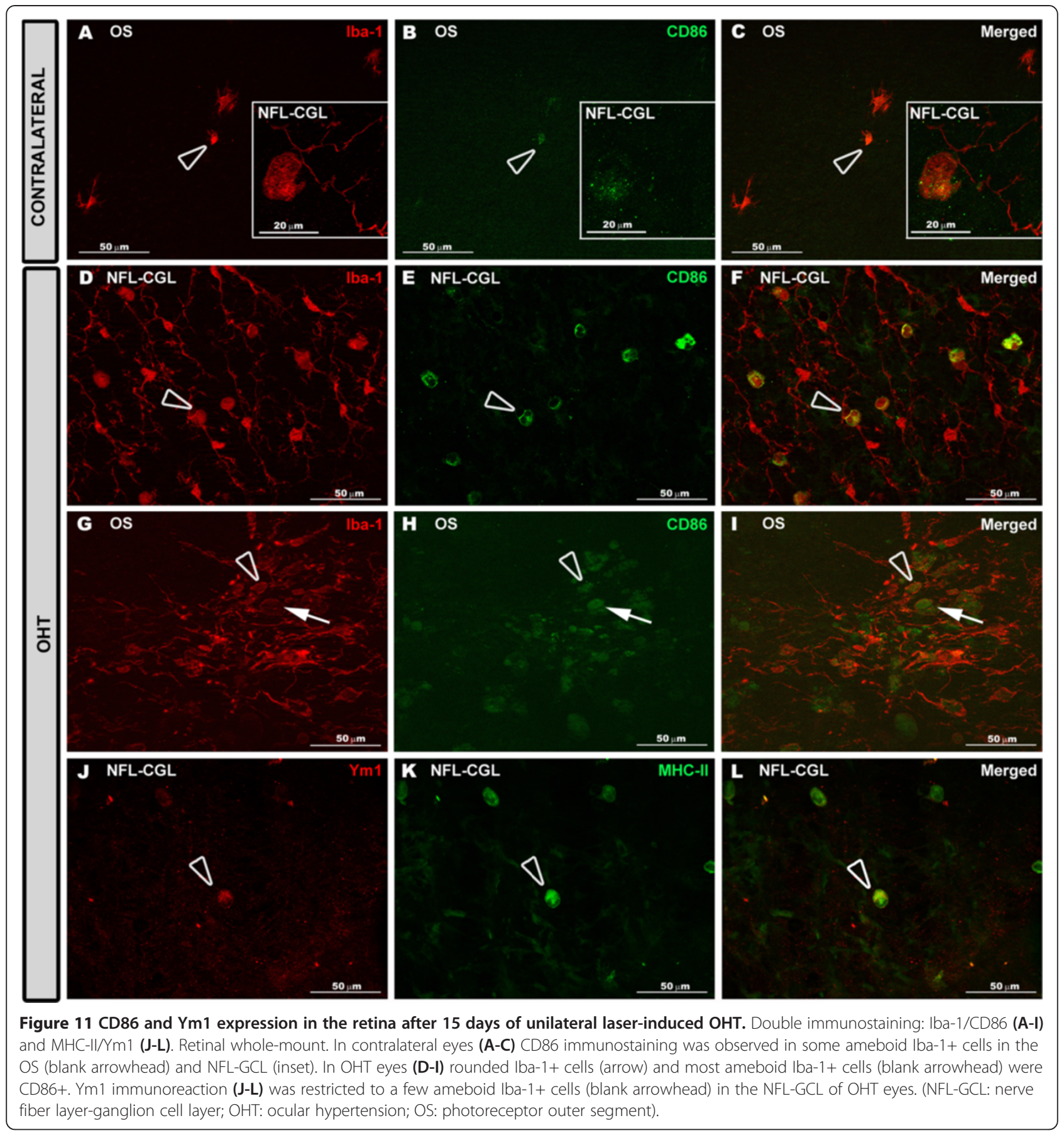

processes from a perpendicular arrangement to one parallel to the retinal surface in both cases. It has been suggested that a characteristic and early feature of microglial activation is their ability to reorient their processes towards the site of injury [66,92]. Notably, this feature was observed in contralateral eyes and the degree of reorientation of processes appeared in an intermediate state between naive and $\mathrm{OHT}$ eyes.

Studies on retinal dystrophies, phototoxicity, and agerelated macular degeneration [61,85,87,89,93-97] have demonstrated that chronic activation of microglia could promote a pro-inflammatory environment that would affect RPE morphology and function [98,99]. Activated Iba-1+ cells in the OS could produce pro-inflammatory factors and chemokines capable of inducing blood-cell recruitment [96] that could at least partly explain the presence of rounded Iba-1+ MHC-II+ CD68+ cells in the subretinal space of $\mathrm{OHT}$ eyes. Another feature supporting the possibility of the outer retina being affected by OHT is the fact that there were dendritic-like Iba- $1+$ cells in the 


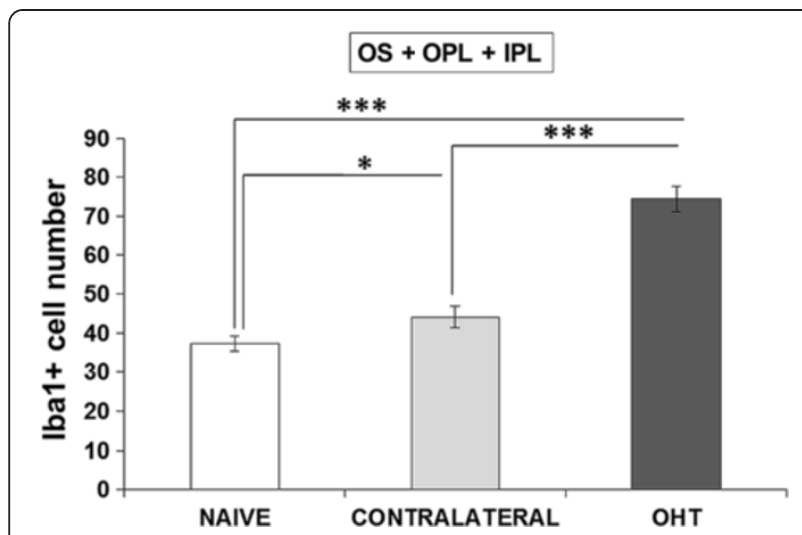

Figure $12 \mathrm{lba}-1+$ cell quantification in OS, OPL, and IPL. Each bar represents the mean \pm SD of the sum of Iba- $1+$ cell number contained in the three retinal layers. ${ }^{* *} P<0.001$ versus naïve and contralateral retinas. ${ }^{*} P<0.05$ versus naïve retinas. (IPL: inner plexiform layer; OHT: ocular hypertension; OPL: outer plexiform layer; OS: photoreceptor outer segment).

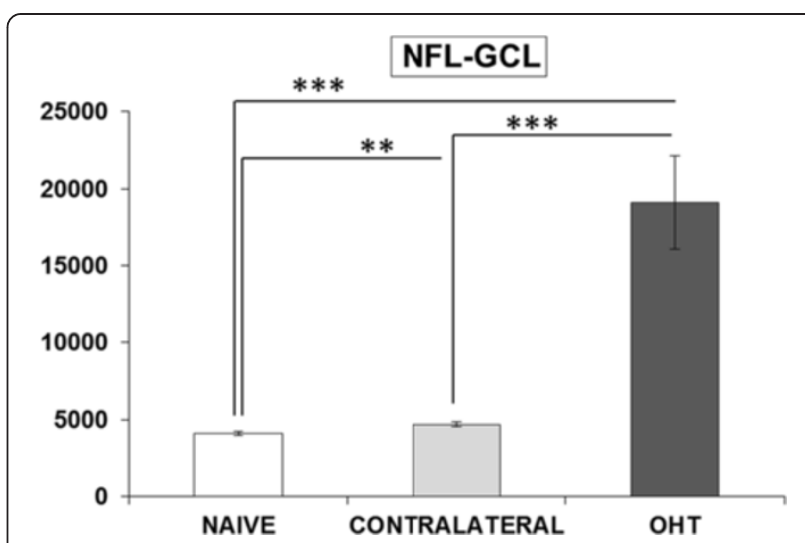

Figure 13 Area of the retina occupied by lba-1+ cells in the NFL-GCL. Each bar represents the mean \pm SD of area of the retina occupied by Iba-1+ cells. ${ }^{* *} P<0.001$ versus naïve and contralateral retinas. ${ }^{* *} P<0.01$ versus naïve retinas. (NFL-GCL: nerve fiber layer-ganglion cell layer; OHT: ocular hypertension; RA: retinal area) (y axis: Iba1-RA $\left(\mu \mathrm{m}^{2}\right)$ ).
OS of OHT eyes in addition to rounded Iba- $1+$ cells. In the mouse retina, dendritic cells are located in areas of the retina where the retinal barriers could be vulnerable and increased numbers of these cells have been associated with structural abnormalities of the RPE in some mice strains [90]. In our Swiss mice, dendritic-like Iba-1+ cells were restricted to the IPL in naïve and contralateral eyes. By contrast, this cell type was found in the OS in addition to IPL in OHT eyes. Evidence supports the idea of cell communication among retinal microglia, even between microglia in the subretinal space and in the inner retina $[87,98]$. According to this proposal, the presence of rounded- and dendritic-like Iba-1+ cells in the OS of OHT eyes, two cell types with high antigen-presenting capacity, could relate to outer retinal barrier dysfunction.

It has been reported that chronic tissue stress in glaucomatous eyes may lead to increased contact of the retina and optic nerve head tissues with systemic immune cells due to alterations in perivascular barrier [100]. In the present work, numerous rounded Iba-1+CD68+ cells were detected in the NFL-GCL of OHT eyes, located mainly adjacent to the major retinal vessels. Iba-1+ rounded cells close to the vessel have been reported in chimeric mice following retinal damage [101]. In addition, it has been postulated that rounded cells could be monocytes entering the retina due to the breakdown into the blood-ocular barrier described in glaucoma $[88,100]$. In $\mathrm{DBA} / 2 \mathrm{~J}$ animals transendothelial migration of $\mathrm{Iba}-1+$ / CD68+ round cells mediate early damage and their reduction improves neuronal survival [102]. It should be noted that in the contralateral eyes where RGC death has not been reported [43], rounded Iba-1+CD68+ cells in the NFL-GCL were not found.

\section{Microglial increased number}

Microglial proliferation has been reported in glaucoma $[28,30-32,39,42,54,63,103,104]$. In patients with glaucoma, microglial proliferation occurs by the expression of growth factors, such as M-CSF and GM-CSF [105], secreted in part by reactive astrocytes [106]. In the same experimental model used here, we have reported astrocyte activation in contralateral and OHT eyes [36]. Such activation could contribute to the significantly increased number of Iba-1+ cells found in contralateral and OHT retinas in the present work. A higher microglial number in glaucoma could be explained by the mitosis of the resident microglia [101,107] or by the entry into the retina of monocytes/macrophages from the bloodstream that later differentiate into microglial cells $[14,61,84,90,96,101,107-114]$. The mechanism involved in the increased number of microglia observed here is beyond the aim of the present study and deserves further investigation.

Table 1 Iba-1+ cell quantification by retinal layers

\begin{tabular}{cccc}
\hline & OS & OPL & IPL \\
\hline NAIVE & $1.44 \pm 0.38$ & $20.00 \pm 1.16$ & $15.87 \pm 0.87$ \\
CONTRALATERAL & $3.35 \pm 1.09$ & $22.36 \pm 1.28$ & $18.43 \pm 1.26$ \\
OHT & $8.80 \pm 1.43$ & $34.81 \pm 1.41$ & $30.80 \pm 1.59$ \\
\hline
\end{tabular}

Data are presented as the mean number of lba-1+ cells \pm SD. Measurements were made at $20 \times$, giving up an area of $0.1502 \mathrm{~mm}{ }^{2}$ per field analyzed. (IPL: inner plexiform layer; OHT: ocular hypertension; OPL: outer plexiform layer; OS: photoreceptor outer segment). 


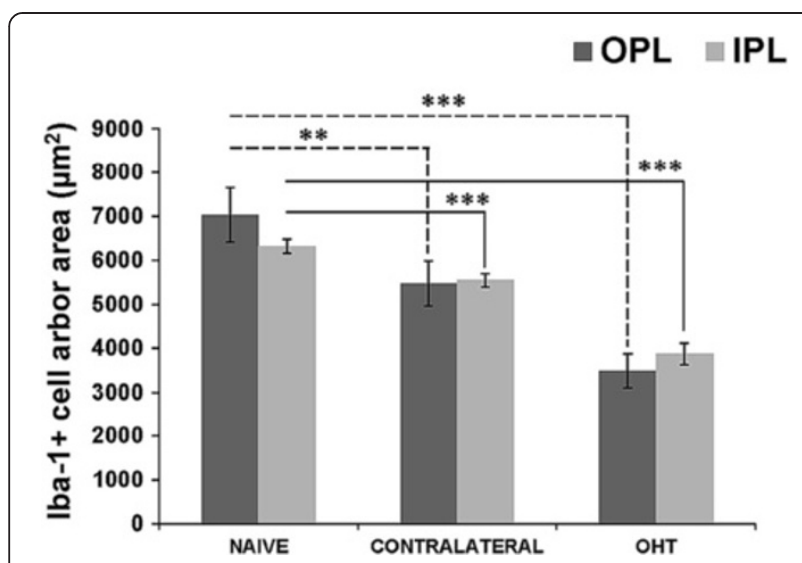

Figure 14 Arbor area of lba 1+ cells in the plexiform layers. Each bar represents the mean \pm SD of arbor area of the lba- $1+$ cells. Dotted lines represent comparison among OPL values: ${ }^{* *} P<0.001$ versus $\mathrm{OHT}$ retinas; ${ }^{* *} P<0.01$ versus contralateral retinas. Solid lines represent comparison among IPL values: ${ }^{* *} P<0.001$ versus contralateral and $\mathrm{OHT}$ retinas. (OHT: ocular hypertension; IPL: inner plexiform layer; OPL: outer plexiform layer; OS photoreceptor outer segment).

\section{Expression of MHC-II, CD68, Ym1, and CD86}

Typically, activated microglial cells are considered to release significant levels of pro-inflammatory molecules, including cytokines and free radicals. Microglia engaged in these responses were also routinely found to exhibit a greater expression of molecules such as CD68, which is a low-density lipoprotein associated with microglial phagocytosis, and MHC-II, in relation to antigen presentation [115]. The expression of MHC-II in glial cells is upregulated in the glaucomatous human retina and optic nerve head $[33,36,100,116-118]$. Similarly, we found MHC-II upregulation in Iba-1+ cells in contralateral and OHT eyes. In this respect, it was remarkable that no differences between them were detected and that in both instances this activation marker was found throughout all retinal layers. By contrast, the CD68 expression pattern differed between contralateral and OHT eyes in that it was higher, involved more cells, and was distributed in all retinal layers in OHT. Chiu et al. [119] reported a correlation between microglia morphology and retinal-ganglion-cell loss in experimental glaucoma. These authors found that fully activated microglia exacerbated RGC loss and that a moderately activated morphology appeared when a neuroprotective agent was given. In the present study, the strongest expression of CD68 in OHT eyes was found in cells displaying features of a fully activated state. CD68 is a member of the scavenger-receptor family. Scavenger receptors typically function to clear cell debris, promote phagocytosis, and mediate the recruitment and activation of macrophages. Thus, the increased expression of CD68 in these OHT eyes seems to be in accordance with the ganglion-cell death reported in this experimental model [43] and the rounded Iba-1+ cells presumably infiltrating the retinal parenchyma (CD68 molecule (Homo sapiens (human); Gene ID: 968; provided by RefSeq, Jul 2008).

Positive immunolabeling for $\mathrm{Ym} 1$ was restricted to a few ameboid Iba-1+ cells in the NFL-GCL of OHT eyes. To determine microglia polarization was not within the scope of the present study and cannot be based on the results of a single surface marker, however, the fact that only a few cells expressed a surface marker of the M2 phenotype could point towards most Iba-1+ cells in this OHT model exerting functions not related to the M2 activation pattern. Moreover, it should be taken into account that data presented here corresponds to 15 days after lasering and that a transient expression of $\mathrm{Ym} 1$, as has been reported during brain ischemic injury in mice $[120,121]$, cannot be ruled out.

As mentioned above, widespread upregulation of MHC-II in Iba-1+ cells took place in all retinal layers in contralateral and OHT eyes, however, in both instances CD86 immunolabeling was restricted to ameboid and rounded Iba-1+ cells in the NFL-GCL and in the OS. CD86- Iba-1+ cells could prevent the functional activation of $\mathrm{T}$ cells by their omission of co-stimulation, which may result in T-cell apoptosis or anergy, thus downregulating the immune response $[121,122]$.

\section{Contralateral eyes: an overview}

After tissue injury, reactive microglia are capable of undergoing migratory and proliferative processes through the brain or retina to interact with damaged cells [123]. A noteworthy point of this study was the observation that, in untreated contralateral eyes as well as in OHT eyes, besides the increase in microglia cell number and displacement of these cells across retinal layers, there were additional signs of Iba-1+ cell activation. As in OHT eyes, microglia reactivity affected all retinal layers. It should be mentioned that IOP levels in contralateral eyes did not differ significantly from naïve eyes and that in the same experimental model of OHT used here and at the same time point of the death of mouse, neither RGC death or degeneration nor ERG alteration has been reported [43]. Nevertheless, Iba-1+ cells in contralateral eyes share their greater numbers with OHT eyes, higher level of branching, process shortening and thickening, migration to the nearest nuclear layer, reorientation of processes, smaller arbor area in the plexiform layers, increased retinal area occupied by Iba-1+ cells in the NFL-GCL, and upregulation of MHC-II and CD68 in comparison with naïve eyes. Some of these phenomena are related to a proinflammatory environment, synapse disruption, or neuronal damage, among other factors. It has been reported that the degree of microglial activation varies with the severity of neuronal injury and that the mildest injuries may only cause hyper-ramification of microglia [71]. 
However, as mentioned above, in addition to a widespread higher level of branching, Iba-1+ cells in contralateral eyes exhibited several signs of activation reported in neuroinflammatory diseases, thus reflecting the presence of potentially damaging signals in the tissue that could enhance retinal neural death $[46,86,124,125]$.

\section{Conclusions}

In conclusion, in this study, we show descriptively and quantitatively the differential behavior of activated microglial cells in the different layers of the retina 15 days after unilateral laser-induced OHT. Our data support the notion that, in glaucomatous degeneration, damage extends beyond the GCL and that this is also observed in contralateral untreated eyes. OHT eyes, as well as contralateral eyes, showed several signs of microglial activation, although these were stronger in the former. For this, further dissection of the functional significance of microglial activation in glaucoma onset and progression is mandatory. In addition, contralateral eyes appear to be have potential for discovering points of intervention to which future therapeutics can be directed.

\section{Additional file}

Additional file 1: Table S1. CD68, CD86, Ym1, and MHC-II expression in lba-1+ cell types in the retina after 15 days of unilateral laser-induced OHT.

\begin{abstract}
Abbreviations
GCL: Ganglion cell layer; Iba-1: Ionized calcium binding adaptor molecule 1; Iba1-RA: Area of the retina occupied by Iba-1+ cells; INL: Inner nuclear layer; IOP: Intraocular pressure; IPL: Inner plexiform layer; MHC-II: Major histocompatibility complex class II molecule; NFL-GCL: Nerve fiber layer-ganglion cell layer; OHT: Ocular hypertension; ONL: Outer nuclear layer; OPL: Outer plexiform layer; OS: Photoreceptor outer segment; PB: Phosphate buffer; PL: Plexiform layers; RGC: Retinal ganglion cells; Ym1: also known as CHI3L3 (Chitinase-3-like protein 3) or ECF-L (Eosinophil chemotactic factor-L).
\end{abstract}

\section{Competing interests}

The authors declare that they have no competing interests.

\section{Authors' contributions}

FJVS, MAT, MPVP and MVS carried out the development for the animal model and the IOP measurement. AIR, AT, BIG, BR, JMR, JJS, and RdH contributed to immunhistochemical study, analysis and interpretation of data, drafting the manuscript and revising it critically. All authors read and approved the final manuscript.

\section{Acknowledgments}

This work was supported by RETICs ENFERMEDADES OCULARES: 'Prevención, detección precoz y tratamiento de la patología ocular prevalente degenerativa y crónica (OFTARED, grant numbers RD12/0034/0002 and RD12/0034/0014, ISCIII, Spanish Ministry of Science and Innovation). The funders had no role in study design, data collection and analysis, decision to publish, or preparation of the manuscript.

The authors would like to thank Desirée Contreras and Francisca Vargas for technical assistance, and David Nesbitt for correcting the English version of this work.

\section{Author details}

'Instituto de Investigaciones Oftalmológicas Ramón Castroviejo, Facultad de Medicina, Pab VI, 4a, Avenida Complutense s/n, Universidad Complutense de
Madrid, 28040 Madrid, Spain. ${ }^{2}$ Departamento de Oftalmología y ORL, Facultad de Medicina, Avenida Complutense s/n, Universidad Complutense de Madrid, 28040 Madrid, Spain. ${ }^{3}$ Facultad de Óptica y Optometría, Avda. Arcos de Jalón, 118, Universidad Complutense de Madrid, 28037 Madrid, Spain. ${ }^{4}$ Experimental Ophthalmology Laboratory, Department of Ophthalmology, College of Medicine, Calle Campus Universitario s/n, University of Murcia, Regional Campus of International Excellence: Campus Mare Nostrum, Murcia Institute of Bio-Health Research (IMIB), E-30100 Murcia, Spain.

Received: 29 May 2014 Accepted: 15 July 2014

Published: 26 July 2014

References

1. Sommer A: Intraocular pressure and glaucoma. Am J Ophthalmol 1989, 107:186.

2. Gordon MO, Beiser JA, Brandt JD, Heuer DK, Higginbotham EJ, Johnson CA, Keltner JL, Miller JP, Parrish I, Richard K: The ocular hypertension treatment study: baseline factors that predict the onset of primary open-angle glaucoma. Arch Ophthalmol 2002, 120:714.

3. Heijl A, Leske MC, Bengtsson B, Hyman L, Bengtsson B, Hussein M: Reduction of intraocular pressure and glaucoma progression: results from the early manifest glaucoma trial. Arch Ophthalmol 2002, 120:1268-1279.

4. Leske MC, Heijl A, Hussein M, Bengtsson B, Hyman L, Komaroff E: Factors for glaucoma progression and the effect of treatment: the early manifest glaucoma trial. Arch Ophthalmol 2003, 121:48-56.

5. Wax MB, Tezel G, Yang J, Peng G, Patil RV, Agarwal N, Sappington RM, Calkins DJ: Induced autoimmunity to heat shock proteins elicits glaucomatous loss of retinal ganglion cell neurons via activated T-cell-derived fas-ligand. J Neurosci 2008, 28:12085-12096.

6. Gramlich OW, Beck S, und Hohenstein-Blaul N, von Thun N, Boehm N, Ziegler A, Vetter JM, Pfeiffer N, Grus FH: Enhanced insight into the autoimmune component of glaucoma: IgG autoantibody accumulation and pro-inflammatory conditions in human glaucomatous retina. PLOS One 2013, 8:e57557.

7. Sappington RM, Sidorova T, Long DJ, Calkins DJ: TRPV1: contribution to retinal ganglion cell apoptosis and increased intracellular $\mathrm{Ca} 2+$ with exposure to hydrostatic pressure. Invest Ophthalmol Vis Sci 2009, 50:717-728.

8. McKinnon SJ, Goldberg LD, Peeples P, Walt JG, Bramley TJ: Current management of glaucoma and the need for complete therapy. Am J Manag Care 2008, 14:S20-S27.

9. Crish SD, Sappington RM, Inman DM, Horner PJ, Calkins DJ: Distal axonopathy with structural persistence in glaucomatous neurodegeneration. Proc Natl Acad Sci U S A 2010, 107:5196-5201.

10. Libby RT, Li Y, Savinova OV, Barter J, Smith RS, Nickells RW, John SW: Susceptibility to neurodegeneration in a glaucoma is modified by Bax gene dosage. PLoS Genet 2005, 1:e4.

11. Streit WJ, Conde JR, Fendrick SE, Flanary BE, Mariani CL: Role of microglia in the central nervous system's immune response. Neurol Res 2005, 27:685-691.

12. Bosco A, Steele MR, Vetter ML: Early microglia activation in a mouse model of chronic glaucoma. J Comp Neurol 2011, 519:599-620.

13. Lee JE, Liang KJ, Fariss RN, Wong WT: Ex vivo dynamic imaging of retinal microglia using time-lapse confocal microscopy. Invest Ophthalmol Vis Sci 2008, 49:4169-4176.

14. Tambuyzer BR, Ponsaerts $P$, Nouwen EJ: Microglia: gatekeepers of central nervous system immunology. J Leukoc Biol 2009, 85:352-370.

15. Thanos S: The relationship of microglial cells to dying neurons during natural neuronal cell death and axotomy-induced degeneration of the Rat retina. Eur J Neurosci 1991, 3:1189-1207.

16. Zhang C, Tso MO: Characterization of activated retinal microglia following optic axotomy. J Neurosci Res 2003, 73:840-845.

17. Garcia-Valenzuela E, Sharma SC, Piña AL: Multilayered retinal microglial response to optic nerve transection in rats. Mol Vis 2005, 11:225-231.

18. Baptiste D, Powell K, Jollimore C, Hamilton C, LeVatte T, Archibald M, Chauhan B, Robertson G, Kelly M: Effects of minocycline and tetracycline on retinal ganglion cell survival after axotomy. Neuroscience 2005, 134:575-582.

19. Sobrado-Calvo P, Vidal-Sanz M, Villegas-Perez MP: Rat retinal microglial cells under normal conditions, after optic nerve section, and after optic 
nerve section and intravitreal injection of trophic factors or macrophage inhibitory factor. J Comp Neurol 2007, 501:866-878.

20. Villegas-Perez MP, Vidal-Sanz M, Rasminsky M, Bray GM, Aguayo AJ: Rapid and protracted phases of retinal ganglion cell loss follow axotomy in the optic nerve of adult rats. J Neurobiol 1993, 24:23-36

21. Peinado-Ramon $P$, Salvador M, Villegas-Perez MP, Vidal-Sanz M: Effects of axotomy and intraocular administration of NT-4, NT-3, and brain-derived neurotrophic factor on the survival of adult rat retinal ganglion cells. A quantitative in vivo study. Invest Ophthalmol Vis Sci 1996, 37:489-500.

22. Thanos S, Pavlidis C, Mey J, Thiel HJ: Specific transcellular staining of microglia in the adult rat after traumatic degeneration of carbocyaninefilled retinal ganglion cells. Exp Eye Res 1992, 55:101-117.

23. Thanos S, Pavlidis C, Mey J, Thiel HJ: Effect of brain-derived neurotrophic factor on mouse axotomized retinal ganglion cells and phagocytic microglia. Invest Ophthalmol Vis Sci 2013, 54:974-985.

24. Davies MH, Eubanks JP, Powers MR: Microglia and macrophages are increased in response to ischemia-induced retinopathy in the mouse retina. Mol Vis 2006, 12:467-477.

25. Zhang C, Lam TT, Tso MO: Heterogeneous populations of microglia/ macrophages in the retina and their activation after retinal ischemia and reperfusion injury. Exp Eye Res 2005, 81:700-709.

26. Selles-Navarro I, Villegas-Perez MP, Salvador-Silva M, Ruiz-Gomez JM, Vidal-Sanz M: Retinal ganglion cell death after different transient periods of pressure-induced ischemia and survival intervals. A quantitative in vivo study. Invest Ophthalmol Vis Sci 1996, 37:2002-2014.

27. Lafuente MP, Villegas-Perez MP, Sobrado-Calvo P, Garcia-Aviles A, Miralles de Imperial J, Vidal-Sanz M: Neuroprotective effects of alpha(2)-selective adrenergic agonists against ischemia-induced retinal ganglion cell death. Invest Ophthalmol Vis Sci 2001, 42:2074-2084.

28. Wang X, Sam-Wah Tay S, Ng Y: Nitric oxide, microglial activities and neuronal cell death in the lateral geniculate nucleus of glaucomatous rats. Brain Res 2000, 878:136-147.

29. Chauhan BC, Pan J, Archibald ML, LeVatte TL, Kelly ME, Tremblay F: Effect of intraocular pressure on optic disc topography, electroretinography, and axonal loss in a chronic pressure-induced rat model of optic nerve damage. Invest Ophthalmol Vis Sci 2002, 43:2969-2976.

30. Naskar R, Wissing M, Thanos S: Detection of early neuron degeneration and accompanying microglial in the retina of a rat model of glaucoma. Invest Ophthalmol Vis Sci 2002, 43:2962-2968.

31. Inman DM, Horner PJ: Reactive nonproliferative gliosis predominates in a chronic mouse model of glaucoma. Glia 2007, 55:942-953.

32. Johnson EC, Jia L, Cepurna WO, Doser TA, Morrison JC: Global changes in optic nerve head gene expression after exposure to elevated intraocular pressure in a rat glaucoma model. Invest Ophthalmol Vis Sci 2007, 48:3161-3177.

33. Ebneter A, Casson RJ, Wood JP, Chidlow G: Microglial activation in the visual pathway in experimental glaucoma: spatiotemporal characterization and correlation with axonal injury. Invest Ophthalmol Vis Sci 2010, 51:6448-6460.

34. Son JL, Soto I, Oglesby E, Lopez-Roca T, Pease ME, Quigley HA, Marsh-Armstrong N: Glaucomatous optic nerve injury involves early astrocyte reactivity and late oligodendrocyte loss. Glia 2010, 58:780-789.

35. de Hoz R, Gallego BI, Ramírez Al, Rojas B, Salazar JJ, Valiente-Soriano FJ, Avilés-Trigueros M, Villegas-Perez MP, Triviño A, Vidal-Sanz M: Rod-like microglia Are restricted to eyes with laser-induced ocular hypertension but absent from the microglial changes in the contralateral untreated eye. PLoS One 2013, 8:e83733.

36. Gallego Bl, Salazar JJ, de Hoz R, Rojas B, Ramírez Al, Salinas-Navarro M, Ortín-Martínez A, Valiente-Soriano FJ, Avilés-Trigueros M, Villegas-Perez MP: IOP induces upregulation of GFAP and MHC-II and microglia reactivity in mice retina contralateral to experimental glaucoma. J Neuroinflammation 2012, 9:92

37. Quigley HA: Experimental glaucoma damage mechanism. Arch Ophthalmol 1983, 101:1301-1302

38. Neufeld AH: Microglia in the optic nerve head and the region of parapapillary chorioretinal atrophy in glaucoma. Arch Ophthalmol 1999, 117:1050-1056.

39. Yuan L, Neufeld AH: Activated microglia in the human glaucomatous optic nerve head. J Neurosci Res 2001, 64:523-532

40. Shimazawa M, Yamashima T, Agarwal N, Hara H: Neuroprotective effects of minocycline against in vitro and in vivo retinal ganglion cell damage. Brain Res 2005, 1053:185-194.
41. Levkovitch-Verbin H, Kalev-Landoy M, Habot-Wilner Z, Melamed S: Minocycline delays death of retinal ganglion cells in experimental glaucoma and after optic nerve transection. Arch Ophthalmol 2006, 124:520-526.

42. Bosco A, Inman DM, Steele MR, Wu G, Soto I, Marsh-Armstrong N, Hubbard WC, Calkins DJ, Horner PJ, Vetter ML: Reduced retina microglial activation and improved optic nerve integrity with minocycline treatment in the DBA/2 J mouse model of glaucoma. Invest Ophthalmol Vis Sci 2008, 49:1437-1446

43. Salinas-Navarro M, Alarcon-Martinez L, Valiente-Soriano FJ, Ortin-Martinez A, Jimenez-Lopez M, Aviles-Trigueros M, Villegas-Perez MP, de la Villa P. Vidal-Sanz M: Functional and morphological effects of laser-induced ocular hypertension in retinas of adult albino Swiss mice. Mol Vis 2009, 15:2578-2598

44. Cuenca N, Pinilla I, Fernández-Sánchez L, Salinas-Navarro M, Alarcón-Martínez L, Avilés-Trigueros M, de la Villa P, Miralles de Imperial J, Villegas-Pérez MP, Vidal-Sanz M: Changes in the inner and outer retinal layers after acute increase of the intraocular pressure in adult albino Swiss mice. Exp Eye Res 2010, 91:273-285.

45. Danias J, Kontiola Al, Filippopoulos T, Mittag T: Method for the noninvasive measurement of intraocular pressure in mice. Invest Ophthalmol Vis SC 2003, 44:1138-1141.

46. Wang $X, N g$ YK, Tay SS: Factors contributing to neuronal degeneration in retinas of experimental glaucomatous rats. J Neurosci Res 2005, 82:674-689.

47. Vidal-Sanz M, Salinas-Navarro M, Nadal-Nicolas FM, Alarcon-Martinez L, Valiente-Soriano FJ, de Imperial JM, Aviles-Trigueros M, Agudo-Barriuso M, Villegas-Perez MP: Understanding glaucomatous damage: anatomical and functional data from ocular hypertensive rodent retinas. Prog Retin Eye Res 2012, 31:1-27.

48. Aihara M, Lindsey JD, Weinreb RN: Twenty-four-hour pattern of mouse intraocular pressure. Exp Eye Res 2003, 77:681-686.

49. Drouyer E, Dkhissi-Benyahya O, Chiquet C, WoldeMussie E, Ruiz G, Wheeler LA, Denis P, Cooper HM: Glaucoma alters the circadian timing system. PLoS One 2008, 3:e3931.

50. Ramírez JM, Triviño A, Ramírez Al, Salazar JJ, García-Sánchez J: Immunohistochemical study of human retinal astroglia. Vision Res 1994, 34:1935-1946.

51. Triviño A, De Hoz R, Salazar JJ, Ramírez Al, Rojas B, Ramírez JM: Distribution and organization of the nerve fiber and ganglion cells of the human choroid. Anat Embryol (Berl) 2002, 205:417-430.

52. de Hoz R, Gallego BI, Rojas B, Ramirez Al, Salazar JJ, Triviño A, de Gracia P, Ramirez JM: A new automatic method for microglial-cell quantification in whole-mount mouse retinas. Acta Ophthalmol 2013, 91:0.

53. Ramírez Al, Salazar JJ, de Hoz R, Rojas B, Gallego Bl, Salinas-Navarro M, Alarcón-Martínez L, Ortín-Martínez A, Avilés-Trigueros M, Vidal-Sanz M, Trivino A, Ramírez JM: Quantification of the effect of different levels of IOP in the astroglia of the rat retina ipsilateral and contralateral to experimental glaucoma. Invest Ophthalmol Vis Sci 2010, 51:5690-5696.

54. Lam T, Kwong JMK, Tso MOM: Early glial responses after acute elevated intraocular pressure in rats. Invest Ophthalmol Vis Sci 2003, 44:638-645.

55. Nork TM, Ver Hoeve JN, Poulsen GL, Nickells RW, Davis MD, Weber AJ, Vaegan Sarks SH, Lemley HL, Millecchia LL: Swelling and loss of photoreceptors in chronic human and experimental glaucomas. Arch Ophthalmol 2000, 118:235-245.

56. Grozdanic SD, Betts DM, Sakaguchi DS, Allbaugh RA, Kwon YH, Kardon RH: Laser-induced mouse model of chronic ocular hypertension. Invest Ophthalmol Vis Sci 2003, 44:4337-4346.

57. Fortune B, Bui BV, Morrison JC, Johnson EC, Dong J, Cepurna WO, Jia L, Barber S, Cioffi GA: Selective ganglion cell functional loss in rats with experimental glaucoma. Invest Ophthalmol Vis Sci 2004, 45:1854-1862.

58. Grozdanic SD, Kwon YH, Sakaguchi DS, Kardon RH, Sonea IM: Functional evaluation of retina and optic nerve in the rat model of chronic ocular hypertension. Exp Eye Res 2004, 79:75-83.

59. Holcombe DJ, Lengefeld N, Gole GA, Barnett NL: Selective inner retinal dysfunction precedes ganglion cell loss in a mouse glaucoma model. Br J Ophthalmol 2008, 92:683-688.

60. Nimmerjahn A, Kirchhoff F, Helmchen F: Resting microglial cells are highly dynamic surveillants of brain parenchyma in vivo. Science 2005, 308:1314-1318.

61. Joly S, Francke M, Ulbricht E, Beck S, Seeliger M, Hirrlinger P, Hirrlinger J, Lang KS, Zinkernagel M, Odermatt B, Samardzija M, Reichenbach A, Grimm C, Reme CE: Cooperative phagocytes: resident microglia and bone 
marrow immigrants remove dead photoreceptors in retinal lesions. Am J Pathol 2009, 174:2310-2323.

62. Karlstetter M, Ebert S, Langmann T: Microglia in the healthy and degenerating retina: Insights from novel mouse models. Immunobiology 2010, 215:685-691

63. Bosco A, Crish SD, Steele MR, Romero CO, Inman DM, Horner PJ, Calkins DJ, Vetter ML: Early reduction of microglia activation by irradiation in a model of chronic glaucoma. PLoS One 2012, 7:e43602.

64. Beynon SB, Walker FR: Microglial activation in the injured and healthy brain: what are we really talking about? Practical and theoretical issues associated with the measurement of changes in microglial morphology Neuroscience 2012, 225:162-171.

65. Nakajima KKohsaka S: Response of microglia to brain injury. In Neuroglia. Edited by Kettenmann H, Ransom BR. Oxford: Oxford University Press; 2005:443-453.

66. Walker FR, Beynon SB, Jones KA, Zhao Z, Kongsui R, Cairns M, Nilsson M: Dynamic structural remodelling of microglia in health and disease: $A$ review of the models, the signals and the mechanisms. Brain Behav Immun 2014, 37:1-14.

67. Streit WJ, Walter SA, Pennell NA: Reactive microgliosis. 1999, 57:563-581.

68. Tremblay M, Majewska AK, Lowery RL: Microglial interactions with synapses are modulated by visual experience. PLoS One 2010, 8:e1000527.

69. Fontainhas AM, Wang M, Liang KJ, Chen S, Mettu P, Damani M, Fariss RN, Li W, Wong WT: Microglial morphology and dynamic behavior is regulated by ionotropic glutamatergic and GABAergic neurotransmission. PLOS One 2011, 6:e15973.

70. Hinwood M, Morandini J, Day TA, Walker FR: Evidence that microglia mediate the neurobiological effects of chronic psychological stress on the medial prefrontal cortex. Cereb Cortex 2012, 22:1442-1454.

71. Wilson MA, Molliver ME: Microglial response to degeneration of serotonergic axon terminals. Glia 1994, 11:18-34.

72. Hurley SD, Coleman PD: Facial nerve axotomy in aged and young adult rats: analysis of the glial response. Neurobiol Aging 2003, 24:511-518.

73. Morrison HW, Filosa JA: A quantitative spatiotemporal analysis of microglia morphology during ischemic stroke and reperfusion. J Neuroinflammation 2013, 10:10-14.

74. Neumann H, Kotter M, Franklin R: Debris clearance by microglia: an essential link between degeneration and regeneration. Brain 2009, 132:288-295.

75. Perry $\mathrm{VH}, \mathrm{O}^{\prime} \mathrm{C}$ onnor $\mathrm{V}$ : The role of microglia in synaptic stripping and synaptic degeneration: a revised perspective. ASN Neuro 2010, 14:e00047.

76. Blinzinger K, Kreutzberg G: Displacement of synaptic terminals from regenerating motoneurons by microglial cells. Cell Tissue Res 1968, 85:145-157.

77. Cho BP, Song DY, Sugama S, Shin DH, Shimizu Y, Kim SS, Kim YS, Joh TH: Pathological dynamics of activated microglia following medial forebrain bundle transection. Glia 2006, 53:92-102.

78. Cao T, Thomas TC, Ziebell JM, Pauly JR, Lifshitz J: Morphological and genetic activation of microglia after diffuse traumatic brain injury in the rat. Neuroscience 2012, 225:65-75.

79. Humphrey MF, Moore SR: Microglial responses to focal lesions of the rabbit retina: correlation with neural and macroglial reactions. Glia 1996, 16:325-341.

80. Roque RS, Imperial CJ, Caldwell RB: Microglial cells invade the outer retina as photoreceptors degenerate in Royal College of Surgeons rats. Invest Ophthalmol Vis Sci 1996, 37:196-203.

81. Harada T, Harada C, Kohsaka S, Wada E, Yoshida K, Ohno S, Mamada H, Tanaka K, Parada LF, Wada K: Microglia-Müller glia cell interactions control neurotrophic factor production during light-induced retinal degeneration. J Neurosci 2002, 22:9228-9236.

82. Hughes EH, Schlichtenbrede FC, Murphy CC, Sarra G, Luthert PJ, Ali RR, Dick $A D$ : Generation of activated sialoadhesin-positive microglia during retinal degeneration. Invest Ophthalmol Vis Sci 2003, 44:2229-2234.

83. Marella $M$, Chabry J: Neurons and astrocytes respond to prion infection by inducing microglia recruitment. J Neurosci 2004, 24:620-627.

84. Lewis GP, Sethi CS, Carter KM, Charteris DG, Fisher SK: Microglial cell activation following retinal detachment: a comparison between species. Mol Vis 2005, 11:491-500.

85. Zeng HY, Zhu XA, Zhang C, Yang LP, Wu LM, Tso MO: Identification of sequential events and factors associated with microglial activation, migration, and cytotoxicity in retinal degeneration in rd mice. Invest Ophthalmol Vis Sci 2005, 46:2992-2999.
86. Zhang C, Shen J, Lam TT, Zeng H, Chiang SK, Yang F, Tso M: Activation of microglia and chemokines in light-induced retinal degeneration. Mol Vis 2005, 11:887-895.

87. Ng TF, Streilein JW: Light-induced migration of retinal microglia into the subretinal space. Invest Ophthalmol Vis Sci 2001, 42:3301-3310.

88. Langmann T: Microglia activation in retinal degeneration. J Leukoc Biol 2007, 81:1345-1351.

89. Santos AM, Martin-Oliva D, Ferrer-Martin RM, Tassi M, Calvente R, Sierra A, Carrasco MC, Marin-Teva JL, Navascues J, Cuadros MA: Microglial response to light-induced photoreceptor degeneration in the mouse retina. J Comp Neurol 2010, 518:477-492.

90. Xu H, Chen M, Mayer EJ, Forrester JV, Dick AD: Turnover of resident retinal microglia in the normal adult mouse. Glia 2007, 55:1189-1198.

91. Xu H, Chen M, Manivannan A, Lois N, Forrester JV: Age-dependent accumulation of lipofuscin in perivascular and subretinal microglia in experimental mice. Aging Cell 2008, 7:58-68.

92. Jonas RA, Yuan TF, Liang YX, Jonas JB, Tay DKC, Ellis-Behnke RG: The spider effect: morphological and orienting classification of microglia in response to stimuli in vivo. PLoS One 2012, 7:e30763.

93. Thanos S: Sick photoreceptors attract activated microglia from the ganglion cell layer: a model to study the inflammatory cascades in rats with inherited retinal dystrophy. Brain Res 1992, 588:21-28.

94. Thanos S, Richter W: The migratory potential of vitally labelled microglial cells within the retina of rats with hereditary photoreceptor dystrophy. Int J Dev Neurosci 1993, 11:671-680.

95. Gupta N, Brown KE, Milam AH: Activated microglia in human retinitis pigmentosa, late-onset retinal degeneration, and age-related macular degeneration. Exp Eye Res 2003, 76:463-471.

96. Combadiere C, Feumi C, Raoul W, Keller N, Rodero M, Pezard A, Lavalette S, Houssier M, Jonet L, Picard E, Debre P, Sirinyan M, Deterre P, Ferroukhi T, Cohen SY, Chauvaud D, Jeanny JC, Chemtob S, Behar-Cohen F, Sennlaub F: CX3CR1-dependent subretinal microglia cell accumulation is associated with cardinal features of age-related macular degeneration. J Clin Invest 2007, 117:2920-2928.

97. Chinnery HR, McLenachan S, Humphries T, Kezic JM, Chen X, Ruitenberg MJ, McMenamin PG: Accumulation of murine subretinal macrophages: effects of age, pigmentation and CX3CR1. Neurobiol Aging 2012, 33:1769-1776.

98. Ma W, Zhao L, Fontainhas AM, Fariss RN, Wong WT: Microglia in the mouse retina alter the structure and function of retinal pigmented epithelial cells: a potential cellular interaction relevant to AMD. PLOS One 2009, 4:e7945.

99. $\mathrm{Xu} \mathrm{H}$, Chen M, Forrester JV: Para-inflammation in the aging retina. Prog Retin Eye Res 2009, 28:348-368.

100. Tezel G, the Fourth ARVO/Pfizer Ophthalmics Research Institute Conference, Working Group: The role of glia, mitochondria, and the immune system in glaucoma. Invest Ophthalmol Vis Sci 2009, 50:1001-1012.

101. Kaneko H, Nishiguchi KM, Nakamura M, Kachi S, Terasaki H: Characteristics of bone marrow-derived microglia in the normal and injured retina. Invest Ophthalmol Vis Sci 2008, 49:4162-4168.

102. Howell GR, Soto I, Zhu X, Ryan M, Macalinao DG, Sousa GL, Caddle LB, MacNicoll KH, Barbay JM, Porciatti V, Anderson MG, Smith RS, Clark AF, Libby RT, John SW: Radiation treatment inhibits monocyte entry into the optic nerve head and prevents neuronal damage in a mouse model of glaucoma. J Clin Invest 2012, 122:1246-1261.

103. Wang X, Tay S, Ng YK: An immunohistochemical study of neuronal and glial cell reactions in retinae of rats with experimental glaucoma. Exp Brain Res 2000, 132:476.

104. Inman DM, Lupien CB, Horner PJ: Manipulating Glia to Protect Retinal Ganglion Cells in Glaucoma. In Glaucoma-Current Clinical and Research Aspects. Edited by Gunvant P. Rijeka, Croatia: InTech; 2011:26-50.

105. Giulian D, Ingeman JE: Colony-stimulating factors as promoters of ameboid microglia. J Neurosci 1988, 8:4707-4717.

106. Aloisi F: Cytokine Production. In Neuroglia. Edited by Kettenmann $\mathrm{H}$, Ransom BR. Oxford, United Kingdom: Oxford University Press; 2005:285-301.

107. Wohl SG, Schmeer CW, Witte OW, Isenmann S: Proliferative response of microglia and macrophages in the adult mouse Eye after optic nerve lesion. Invest Ophthalmol Vis Sci 2010, 51:2686-2696.

108. Kreutzberg GW: Microglia: a sensor for pathological events in the CNS. Trends Neurosci 1996, 19:312-318.

109. Caicedo A, Espinosa-Heidmann DG, Piña Y, Hernandez EP, Cousins SW: Blood-derived macrophages infiltrate the retina and activate Müller glial 
cells under experimental choroidal neovascularization. Exp Eye Res 2005, 81:38-47.

110. Davalos D, Grutzendler J, Yang G, Kim JV, Zuo Y, Jung S, Littman DR, Dustin ML, Gan W: ATP mediates rapid microglial response to local brain injury in vivo. Nat Neurosci 2005, 8:752-758.

111. Kezic J, McMenamin PG: Differential turnover rates of monocyte-derived cells in varied ocular tissue microenvironments. J Leukoc Biol 2008, 84:721-729.

112. Muther PS, Semkova I, Schmidt K, Abari E, Kuebbeler M, Beyer M, Abken H, Meyer KL, Kociok N, Joussen AM: Conditions of retinal glial and inflammatory cell activation after irradiation in a GFP-chimeric mouse model. Invest Ophthalmol Vis Sci 2010, 51:4831-4839.

113. Prinz M, Mildner A: Microglia in the CNS: immigrants from another world. Glia 2011, 59:177-187.

114. Chen L, Yang P, Kijlstra A: Distribution, markers, and functions of retinal microglia. Ocul Immunol Inflamm 2002, 10:27-39.

115. Walker FR, Nilsson M, Jones K: Acute and chronic stress-induced disturbances of microglial plasticity, phenotype and function. Curr Drug Targets 2013, 14:1262-1276.

116. Yang J, Yang P, Tezel G, Patil RV, Hernandez MR, Wax MB: Induction of HLA-DR expression in human lamina cribrosa astrocytes by cytokines and simulated ischemia. Invest Ophthalmol Vis Sci 2001, 42:365-371.

117. Tezel G, Chauhan BC, LeBlanc RP, Wax MB: Immunohistochemical assessment of the glial mitogen-activated protein kinase activation in glaucoma. Invest Ophthalmol Vis Sci 2003, 44:3025-3033.

118. Tezel G, Yang X, Luo C, Peng Y, Sun SL, Sun D: Mechanisms of immune system activation in glaucoma: oxidative stress-stimulated antigen presentation by the retina and optic nerve head glia. Invest Ophthalmol Vis Sci 2007, 48:705-714.

119. Chiu K, Yeung S, So K, Chang RC: Modulation of morphological changes of microglia and neuroprotection by monocyte chemoattractant protein-1 in experimental glaucoma. Cell Mol Immunol 2010, 7:61-68.

120. Chang L, Karin M: Mammalian MAP kinase signalling cascades. Nature 2001, 410:37-40

121. Perego C, Fumagalli S, De Simoni M: Temporal pattern of expression and colocalization of microglia/macrophage phenotype markers following brain ischemic injury in mice. J Neuroinflammation 2011, 8:174.

122. Broderick C, Duncan L, Taylor N, Dick AD: IFN- $\gamma$ and LPS-Mediated IL-10Dependent Suppression of Retinal Microglial Activation. Invest Ophthalmol Vis Sci 2000, 41:2613-2622.

123. Barron KD: The microglial cell. A historical review. J Neurol Sci 1995, 134:57-68.

124. Schuetz $E$, Thanos S: Microglia-targeted pharmacotherapy in retinal neurodegenerative diseases. Curr Drug Targets 2004, 5:619-627.

125. Krady JK, Basu A, Allen CM, Xu Y, LaNoue KF, Gardner TW, Levison SW: Minocycline reduces proinflammatory cytokine expression, microglial activation, and caspase- 3 activation in a rodent model of diabetic retinopathy. Diabetes 2005, 54:1559-1565.

doi:10.1186/1742-2094-11-133

Cite this article as: Rojas et al:: Microglia in mouse retina contralateral to experimental glaucoma exhibit multiple signs of activation in all retinal layers. Journal of Neuroinflammation 2014 11:133.

\section{Submit your next manuscript to BioMed Central and take full advantage of:}

- Convenient online submission

- Thorough peer review

- No space constraints or color figure charges

- Immediate publication on acceptance

- Inclusion in PubMed, CAS, Scopus and Google Scholar

- Research which is freely available for redistribution

Submit your manuscript at www.biomedcentral.com/submit
Ciomed Central 